Purdue University Purdue e-Pubs

$12-2014$

\title{
Computational investigation of microperforated materials: end corrections, thermal effects and fluid- structure interaction
}

J Stuart Bolton

Purdue University, bolton@purdue.edu

Nicholas Kim

Purdue University

Thomas Herdtle

3M Company

Follow this and additional works at: http://docs.lib.purdue.edu/herrick

Bolton, J Stuart; Kim, Nicholas; and Herdtle, Thomas, "Computational investigation of microperforated materials: end corrections, thermal effects and fluid-structure interaction" (2014). Publications of the Ray W. Herrick Laboratories. Paper 118. http://docs.lib.purdue.edu/herrick/118

This document has been made available through Purdue e-Pubs, a service of the Purdue University Libraries. Please contact epubs@purdue.edu for additional information. 


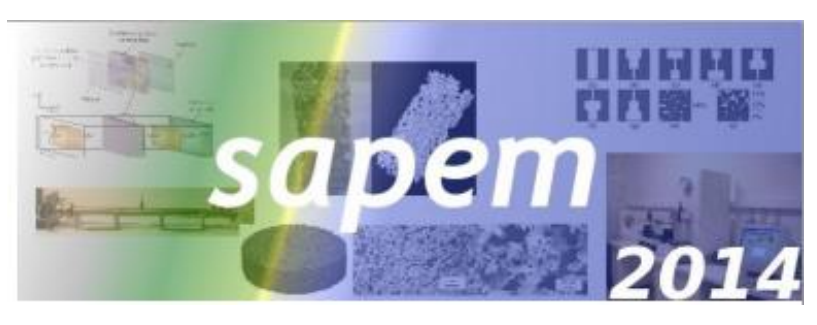

\section{Computational Investigation of Microperforated Materials: End Corrections, Thermal Effects and Fluid-Structure Interaction}

\section{J. Stuart Bolton Nicolas Kim}

Ray W. Herrick Laboratories School of Mechanical Engineering Purdue University West Lafayette, Indiana USA
Thomas Herdtle

3M Corporate R\&D

Predictive Engineering \& Analysis 3M Center

St. Paul, Minnesota USA

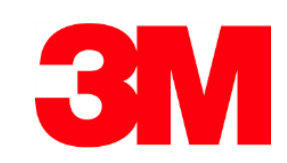




\section{MicroPerforated Films}

$\square$ Suggested by Maa in 1975

- Cylindrical pore + End corrections

- Proposed different formulas for thermally conducting and non-conducting boundaries

$\square$ Models needed for design and prediction

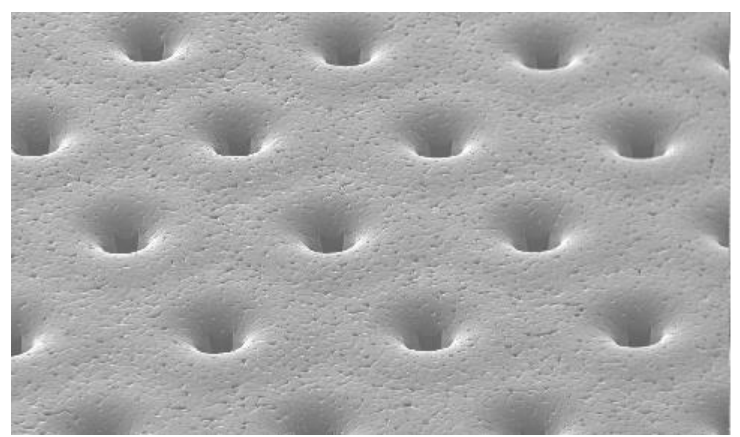

Top view of a microperforated film

o Film transfer impedance needed for transmission matrix calculations

o Need to model non-cylindrical pores

○ Light weight films

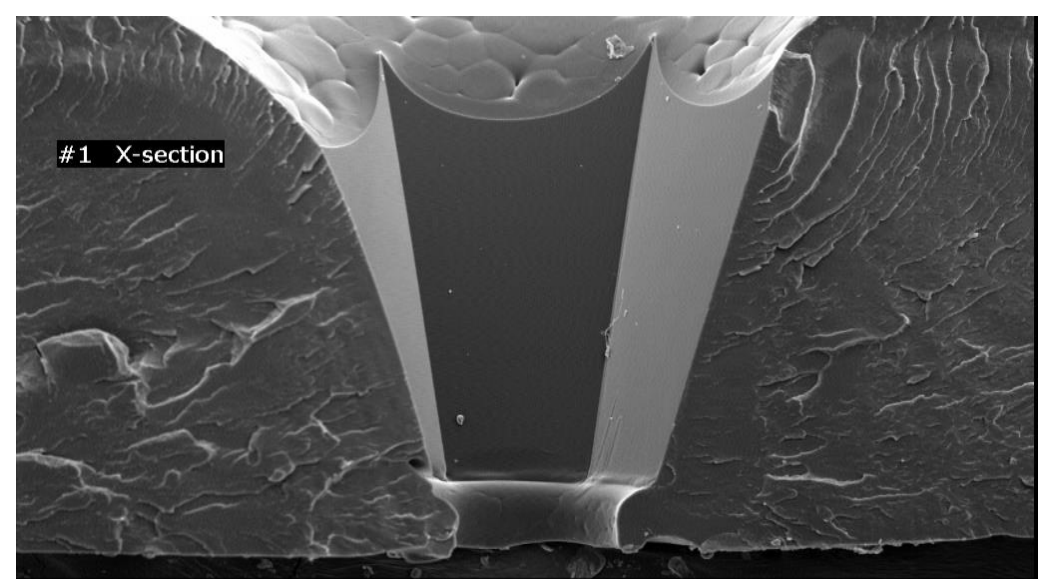

Cross-section of a microperforated film

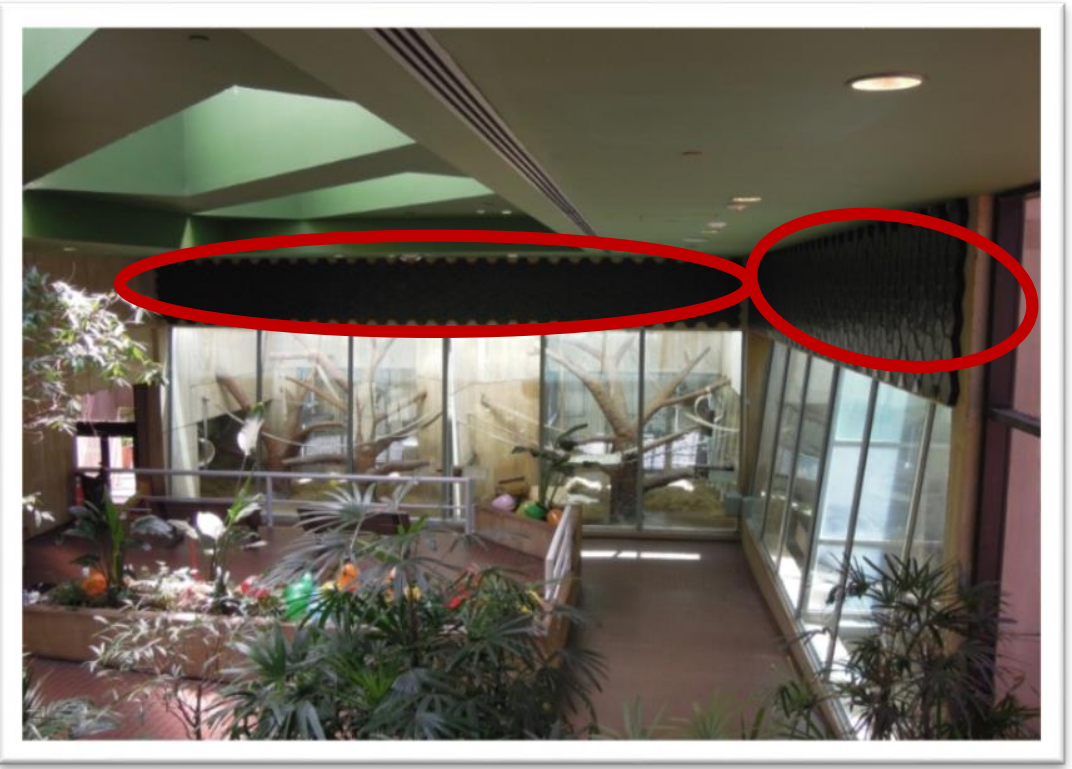

Installed microperforated panels in the Great Ape House of the Smithsonian National Zoo 


\section{National Zoological Park - Great Ape House (Washington DC)}

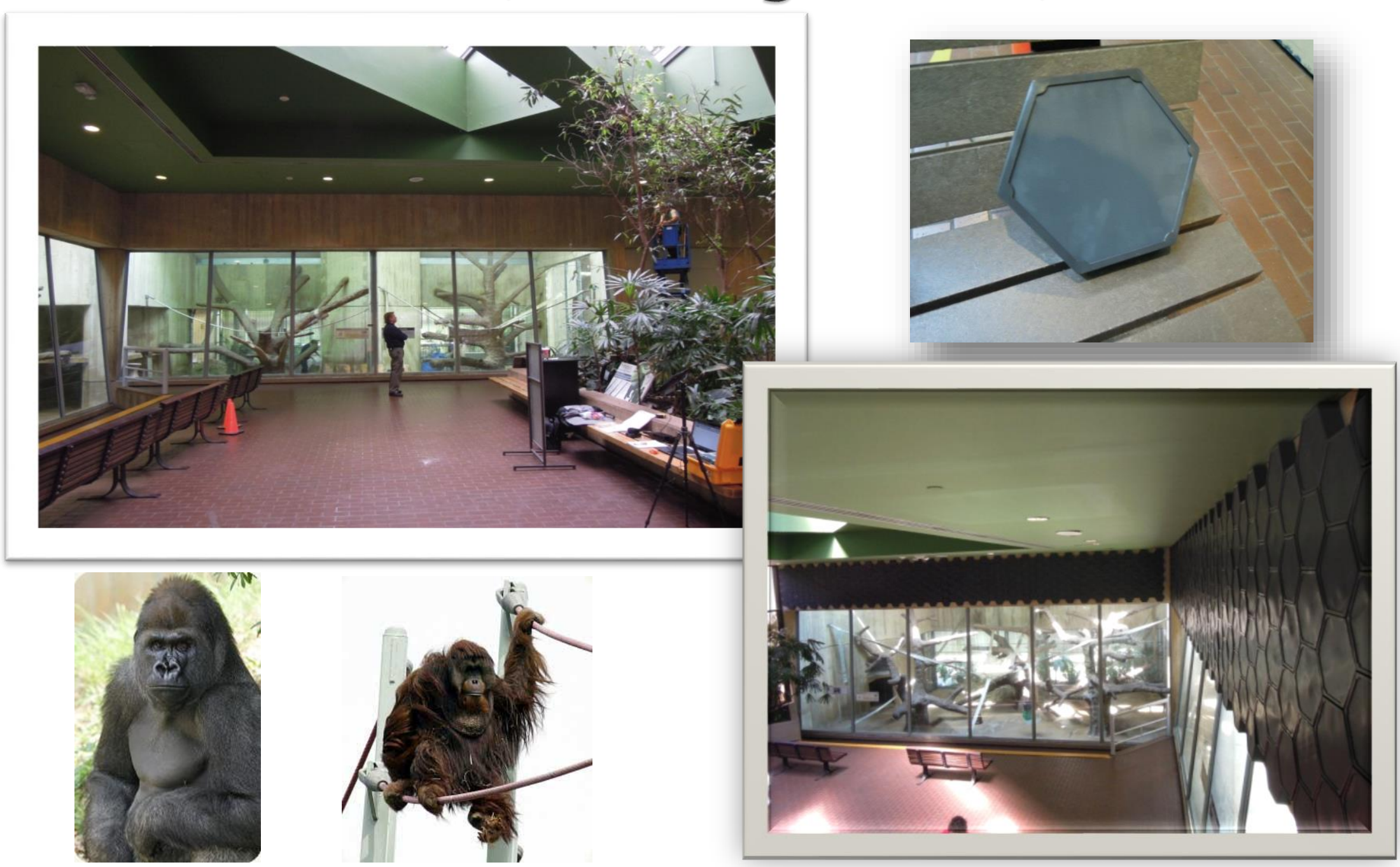

Ryan A. Schultz, J. Stuart Bolton, Jonathan H. Alexander, Stephanie B. Castiglione, Tom P. Hanschen and Ed Bronikowski, "Improving the visitor experience - a noise study and treatment design for the Smithsonian National Zoological Park's Great Ape House," Proceedings of INTER-NOISE 2012, 8 pages, 2012. 


\section{Transfer Impedance of Microperforated Films}

Resistive end corrections

$\square$ Arbitrarily-shaped holes

$\square$ Thermal effects

口Fluid-structure interaction 
将此值与准确值(5)式比较, 二者符合甚好, 最大误差为 $6 \%$ \% (8) 式适合于任何 $x$ 值, 可代替 (6)、(7) 二式为更好的近似值. $x$ 当然不能太大, 在管中出现横波时, 上面的式子就无用了. 管长 $t$ (即穿孔板厚) 如果不是比管径 $d$ 大得多, 就须要加上末端改正值. 占质量的末端 改正值是由末端的声辐射而来, 使有效管长增加 $0.85 d$ (计算两端辐射). 声阻的末端改正 是由于空气出入微管时有一部分沿障板流动, 因而产生磨擦损失所致. 因此可求得 ${ }^{[7]}$, 两端 外都是无穷平面障板时, 声阻率增加 $2 \sqrt{2 \omega \rho \eta}$. 这两部分都应加于 (8) 式.

微穿孔板的声阻抗率, 如果假设各孔间互不影响, 就等于单管的声阻抗率( 包括末端改正 值) 除以穿孔率 $p$ (每单位板面积上孔的总面积). 以空气的特性声阻 $\rho c$ ( $c$ 为声速) 为单位, 穿孔板的相对步阻抗就等于:

$$
z=\frac{Z_{1}}{p \rho c}=r+j \omega m,
$$

其中相对声阻和相对声质量分别为:

$$
r=\frac{32 \mu}{p c} \frac{t}{d^{2}}\left[\sqrt{1+\frac{x^{2}}{32}}+\frac{\sqrt{2} x}{8} \frac{d}{t}\right]
$$


and compare with the exact values, they agree well, the error being no more than 6\%. Eq. (8), as a better approximation of Eq. (5) than Eqs. (6) and (7), is valid for any value of $x$, up to the value where transversal modes begin to appear in the tube.

End corrections must be added, unless the tube length $t$ (i. e., the thickness of the ${ }_{\text {ce }}^{p}$ End correction of the acoustic resistance is produced by the

${ }^{t}$ fr friction loss due to a part of the air moves along the baffle when $n$ bc fr the air flows into and out of the tube, and it may be found ${ }^{[7]}$ that $\frac{\mathrm{e}}{j}$

$\frac{\mathrm{ar}}{\mathrm{r} f}$ the additional part of the acoustic resistance is $2 \sqrt{2 \omega \rho \eta}$, if both sides of the tube are ended in infinite baffles.

tage perforation $p$ (total area of the perforation on a unit area of panel), provided that the interference between the pores $\mathrm{can}_{\varepsilon}$ be neglected. In unit of the characteristic impedance of air, $\rho c$ ( $c$ being the velocity of sound), the relative acoustic impedance is

$$
z=\frac{Z_{1}}{p \rho c}=r+j \omega m
$$




\section{Effect of Viscosity}

The dissipation caused by viscosity can be calculated approximately from the integral ${ }^{9}$

$$
W_{v}=\frac{1}{2} \int_{S} R_{S}\left|U_{S}\right|^{2} d S,
$$

where $U_{S}$ is the tangential velocity amplitude at the surface $S$ calculated from the wave equation neglecting

TABLE III. Measurements of end correction.

\begin{tabular}{cccccc}
\hline \hline & $\begin{array}{c}\text { Measured } \\
\text { slope } S \text { of } \\
\text { curves in } \\
\text { Fig. } 9\end{array}$ & $\begin{array}{c}\text { Total } \\
\text { equivalent } \\
\text { neck length } \\
l \mathrm{~cm}\end{array}$ & $\begin{array}{c}\text { Neck } \\
\text { length } \\
t \mathrm{~cm}\end{array}$ & $\begin{array}{c}\text { End } \\
\text { correction } \\
2 \delta=l-t\end{array}$ & $\begin{array}{c}2 \delta \\
\text { calculated }\end{array}$ \\
\hline 0.36 & $0.40610^{-8}$ & 0.390 & 0.097 & 0.283 & 0.284 \\
0.50 & $0.32410^{-3}$ & 0.430 & 0.051 & 0.379 & 0.387 \\
1.00 & $0.27610^{-8}$ & 0.736 & 0.051 & 0.685 & 0.707 \\
1.40 & $0.24510^{-3}$ & 0.920 & 0.051 & 0.869 & 0.890 \\
2.00 & $0.20710^{-3}$ & 1.110 & 0.051 & 1.059 & 1.12 \\
\hline \hline
\end{tabular}

viscosity, and $R_{S}$ is a "surface resistance." If the radius of curvature of the surface under consideration is large compared to the viscous boundary layer thickness, one can as a good approximation use the resistance calculated from the problem of an oscillatory flow over an infinite plane surface. This resistance is ${ }^{10}$

$$
R_{S}=\frac{1}{2}(2 \mu \rho \omega)^{\frac{1}{3}}
$$

where $\mu$ is the viscosity and $\rho$ the density of the medium. At ordinary room tempertaure, $t \simeq 20^{\circ} \mathrm{C}$, the numerical value for the surface resistance becomes

$$
R_{S} \simeq 0.83 \cdot 10^{-3}(\nu)^{\frac{1}{2}},
$$

$t$ of

by

for

tear

bu-

where $\nu$ is the frequency. 


\section{CFD Approach}

\section{$\square$ Objective}

By using computational fluid dynamics approach, calculate dynamic flow resistance for microperforated panel considering flow through one hole and compare with existing formulation

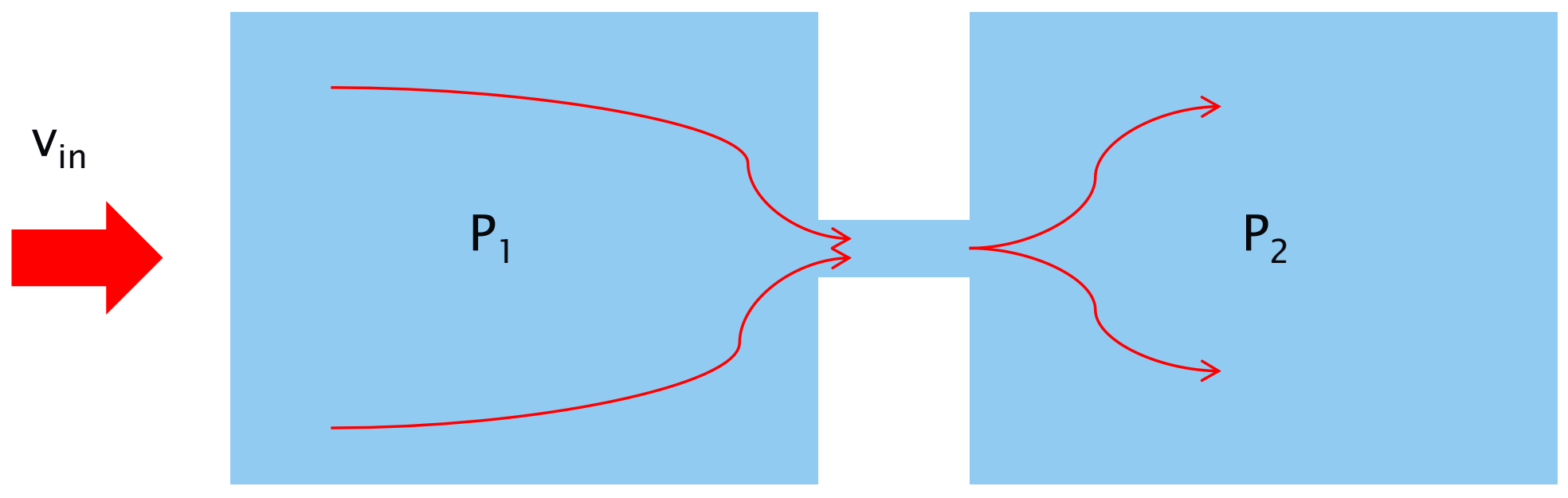

$$
R_{f}=\frac{P_{1}-P_{2}}{v_{i n}}
$$




\section{Geometry and Assumptions}

\section{$\square$ Geometry of CFD model}

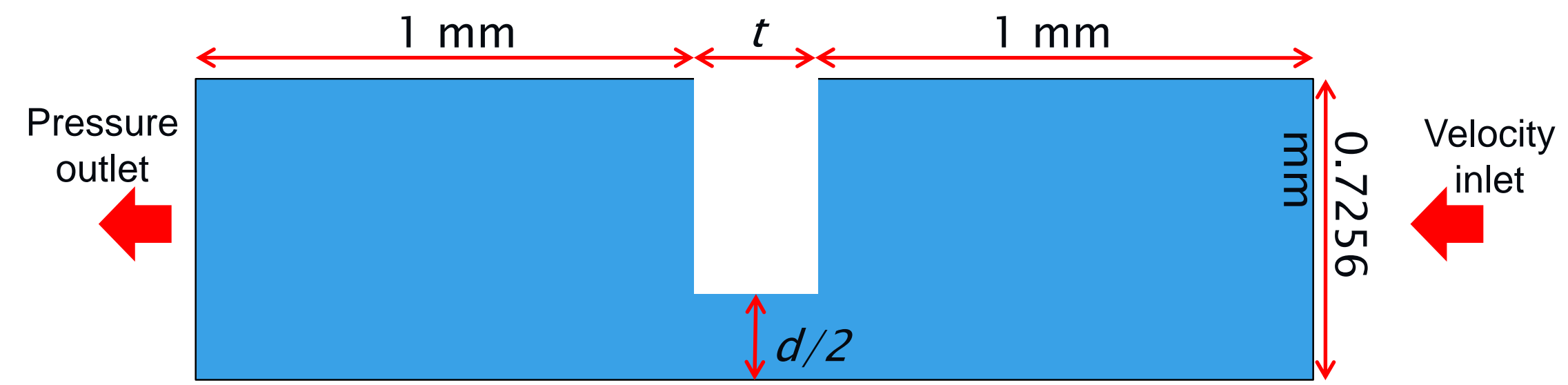

symmetry axis

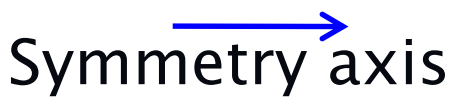
- Incompressible flow in Fluent
- Mesh Interval : $0.005 \mathrm{~mm}$, pressure-based, implicit formulation
o the Green-Gauss node-based method
- SIMPLE for the pressure-velocity coupling method
- STANDARD for pressure
- SECOND-ORDER UPWIND for momentum 


\section{Inlet Velocity and Pressure}
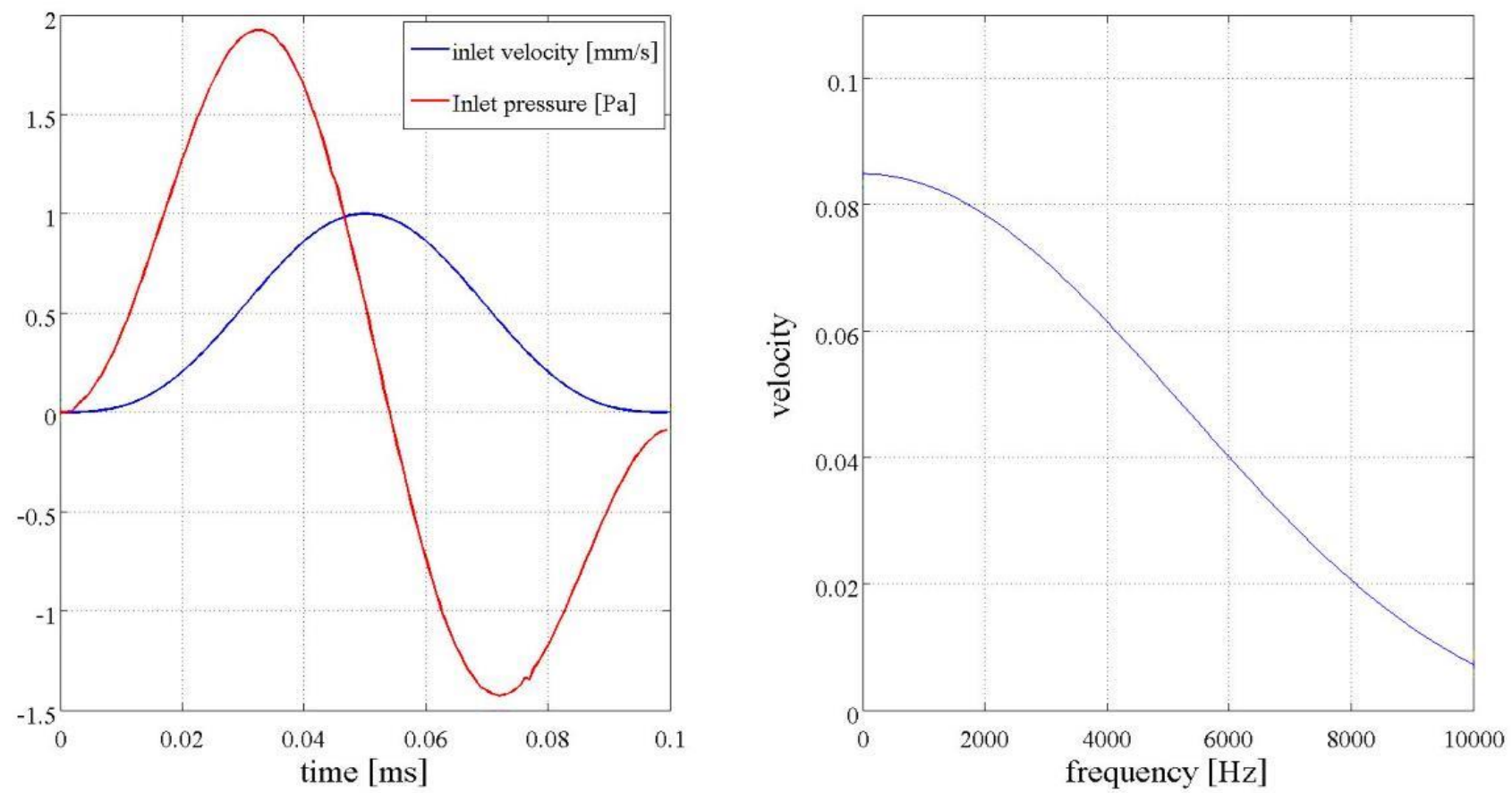

Inlet velocity was chosen to be a Hann windowed, $5 \mathrm{kHz}$ half-sine wave having a maximum value of $1 \mathrm{~mm} / \mathrm{s}$ in order to cover the frequency range up to $10 \mathrm{kHz}$ 


\section{Guo’s Model}

Cylinder Surface

$$
\begin{gathered}
R=\left(\operatorname{Re}\left\{\frac{j \omega t}{\sigma c}\left[1-\frac{2}{k \sqrt{-j}} \frac{J_{1}(k \sqrt{-j})}{J_{0}(k \sqrt{-j})}\right]^{-1}\right\}+\frac{\varrho 2 R_{s}}{\sigma \rho c}\right) \times \rho c \\
k=\sqrt{\frac{\omega \rho_{0}}{4 \eta}} \quad \alpha=2 \quad \text { when smooth end } \\
R_{s}=\frac{\sqrt{2 \omega \rho_{0} \eta}}{2} \quad \alpha=4 \quad \text { when sharp end }
\end{gathered}
$$

\section{Dynamic flow resistance $(R)$ is function of $t, d, \sigma$}

\section{Note that $R_{s} \rightarrow 0$ as $\omega \rightarrow 0$}




\section{Comparison of CFD with Guo's Model}

$\square$ Dynamic flow resistance and flow reactance $(d=0.4064 \mathrm{~mm}$, $t=0.4064 \mathrm{~mm}, \sigma=0.02$ )
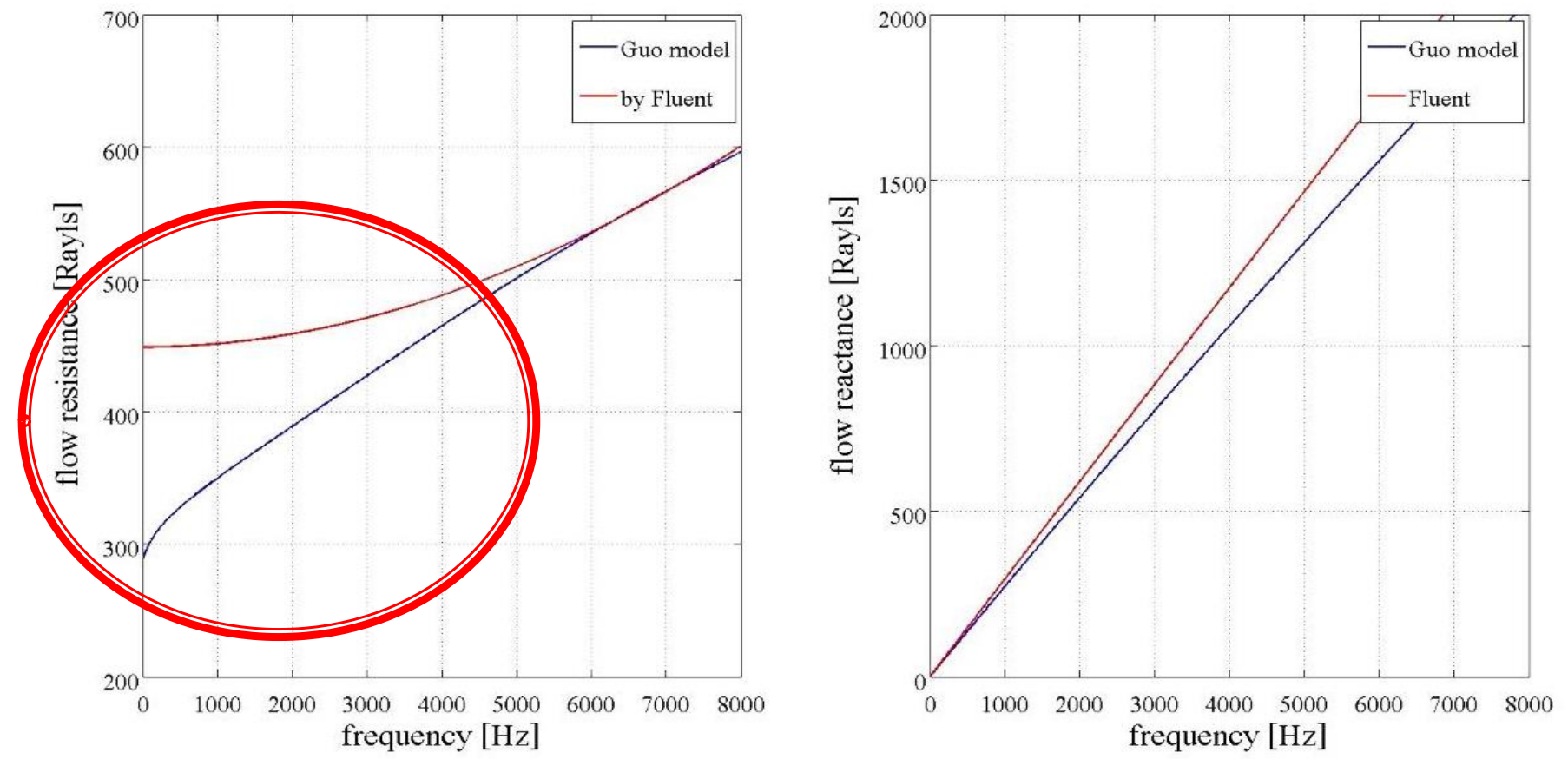

Large difference in flow Resistance in low frequency range

Make $\alpha$, which is defined by Guo et al., a function of frequency to fit with CFD results 


\section{The value of $\alpha$ vs. Frequencv}

Change of thickness

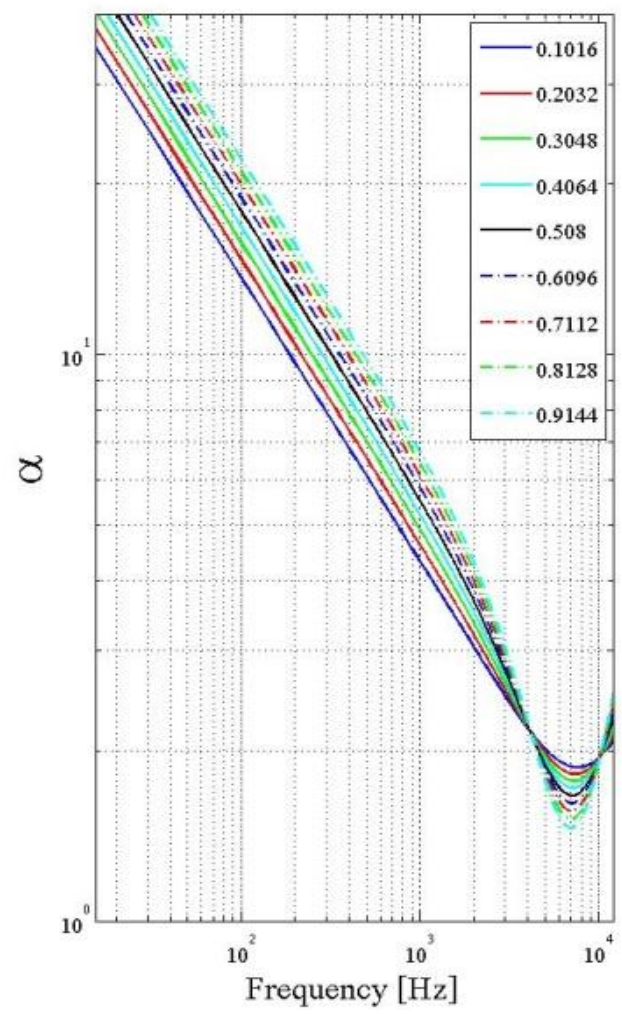

Change of diameter

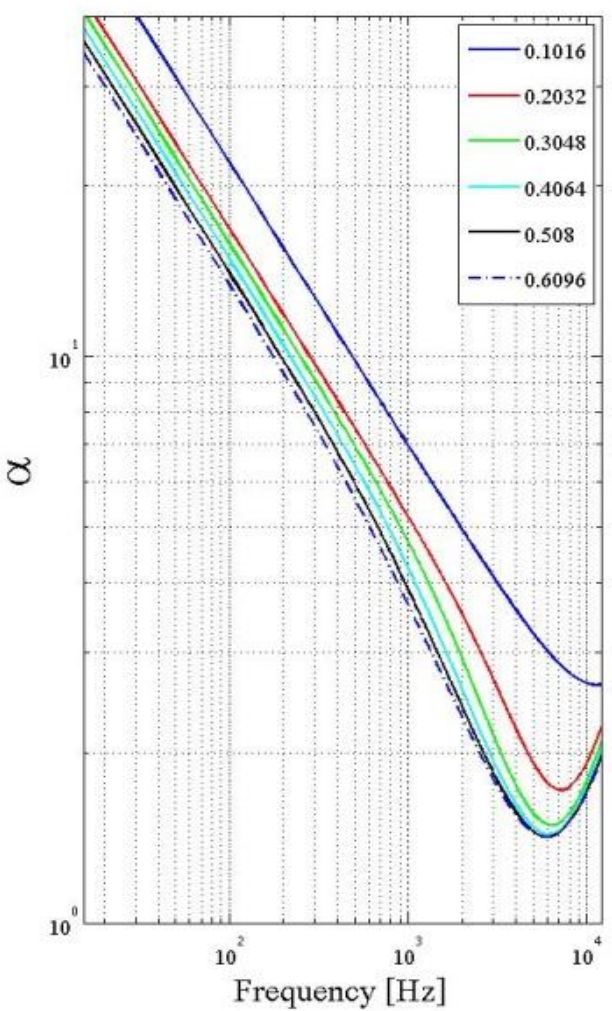

Change of porosity

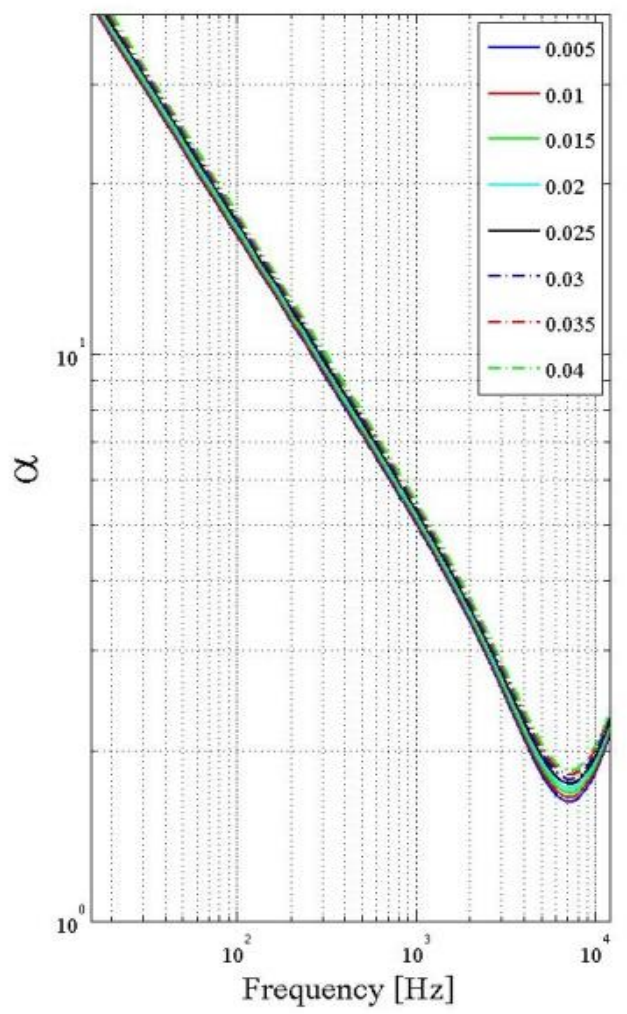

$\circ$ In these graphs, it is shown that $\alpha$ is a function of frequency, thickness, hole diameter, and porosity

- Especially all plot lines are almost parallel below 2 kHz, so we can say that $\alpha$ is approximately proportional to $f^{-0.5}$ 


\section{Revised Formulation}

$R=\left(\operatorname{Re}\left\{\frac{j \omega t}{\sigma c}\left[1-\frac{2}{k \sqrt{-j}} \frac{J_{1}(k \sqrt{-j})}{J_{0}(k \sqrt{-j})}\right]^{-1}\right\}+\frac{\alpha 2 R_{s}}{\sigma \rho c}\right) \times \rho c \quad$ as before

But $\alpha$ should be a function of $\omega, t, d$, and $\sigma$

$\square$ Express $\alpha$ as

$$
\alpha=\beta f^{-0.5}
$$

So that

$$
\beta=\alpha f^{0.5}=f(t, d, \sigma)
$$




\section{Rigid Film - Viscous Losses}

$\underline{\text { Viscous energy losses are proportional to the shear rate }}$ squared

- Losses are concentrated along perforation walls and at the inlet/outlet (resistive end correction)

- Losses are symmetric front-to-back in linear regime (acoustic wave is incident from below)

- Losses decrease as the frequency increases

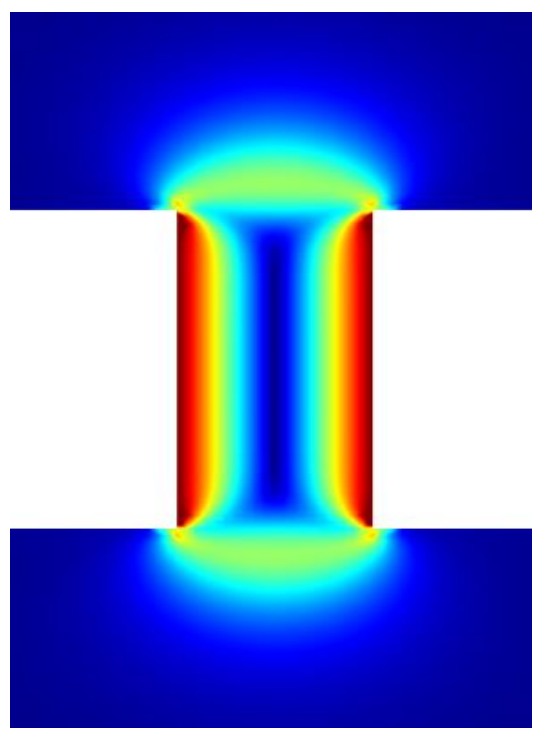

$500 \mathrm{~Hz}$
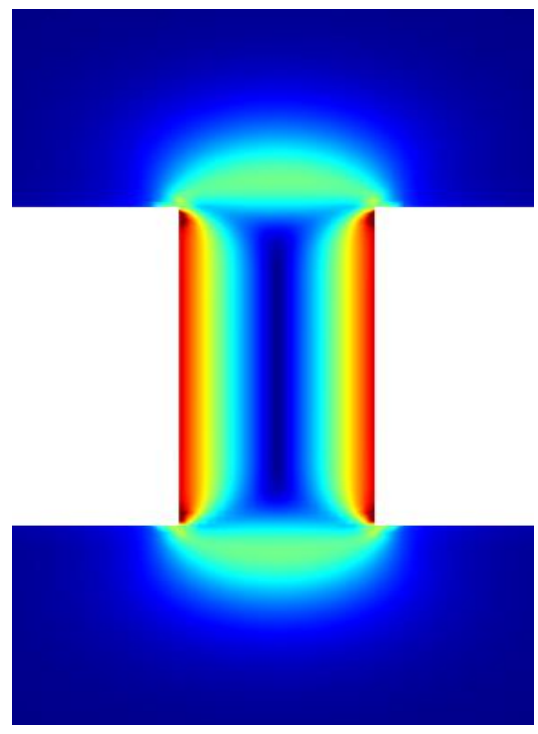

$2,000 \mathrm{~Hz}$

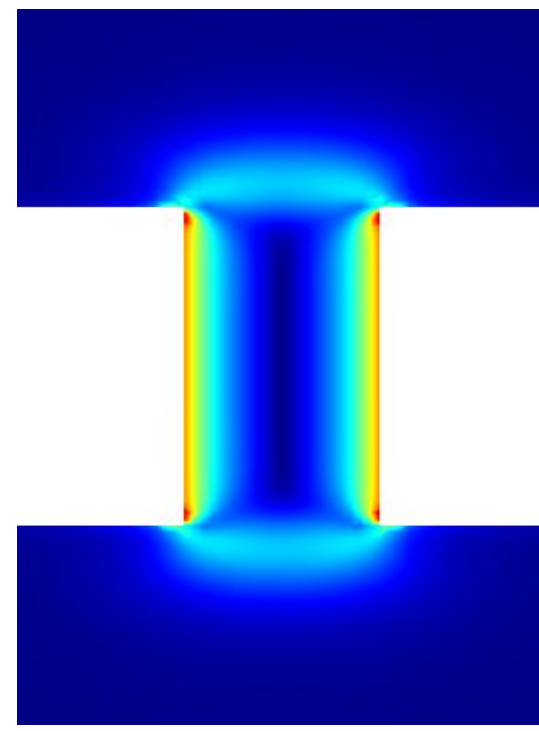

$5,000 \mathrm{~Hz}$

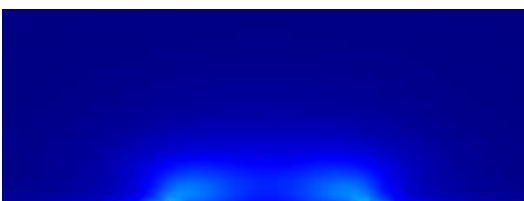

Plots of the square root of viscous losses on a scale from 0 to $15 \sqrt{W / m^{3}}$ 


\section{Resistive End Correction}

$\square$ Energy dissipation occurs within shearing fluid external to the hole

$\square$ Net result is that the resistive end correction is independent of frequency 


\section{CFD Model - Arbitrarily Shaped Holes}

$\checkmark$ FE code Comsol was used primarily

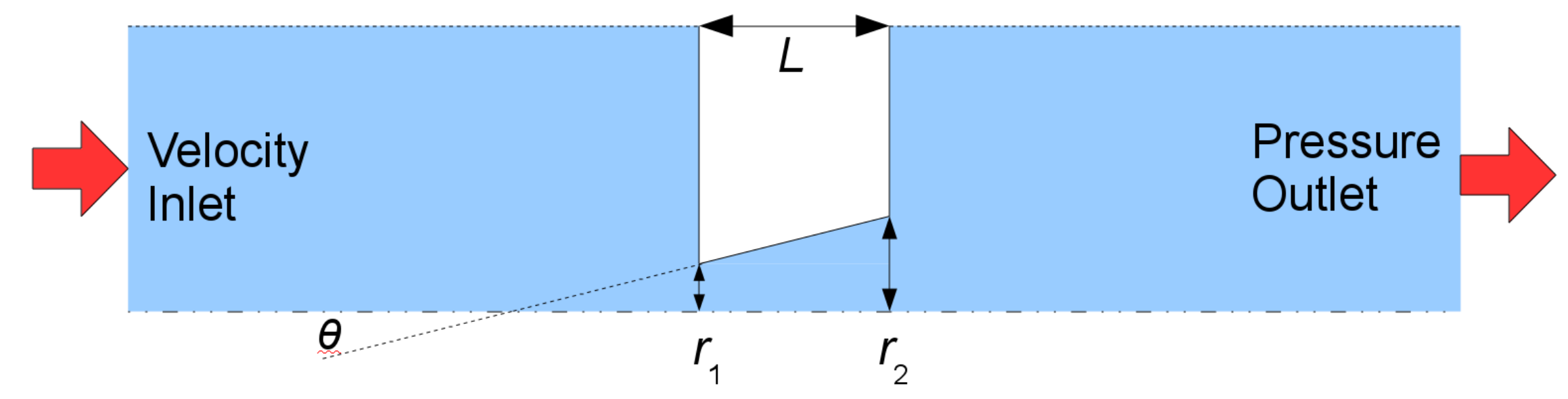

o Inlet: Hann-windowed, $5 \mathrm{kHz}$ half-sine $(0.1 \mathrm{~ms})$

o Run $0.5 \mathrm{~ms}$ for accurate static flow resistance

o Maximum speed of $1 \mathrm{~mm} / \mathrm{s}$

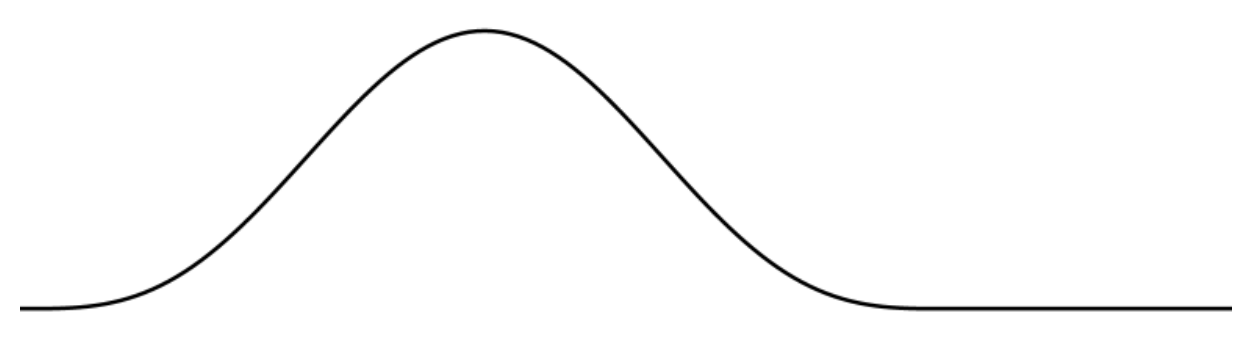




\section{CFD Model - Tapered Hole}

$\square$ Typical Results

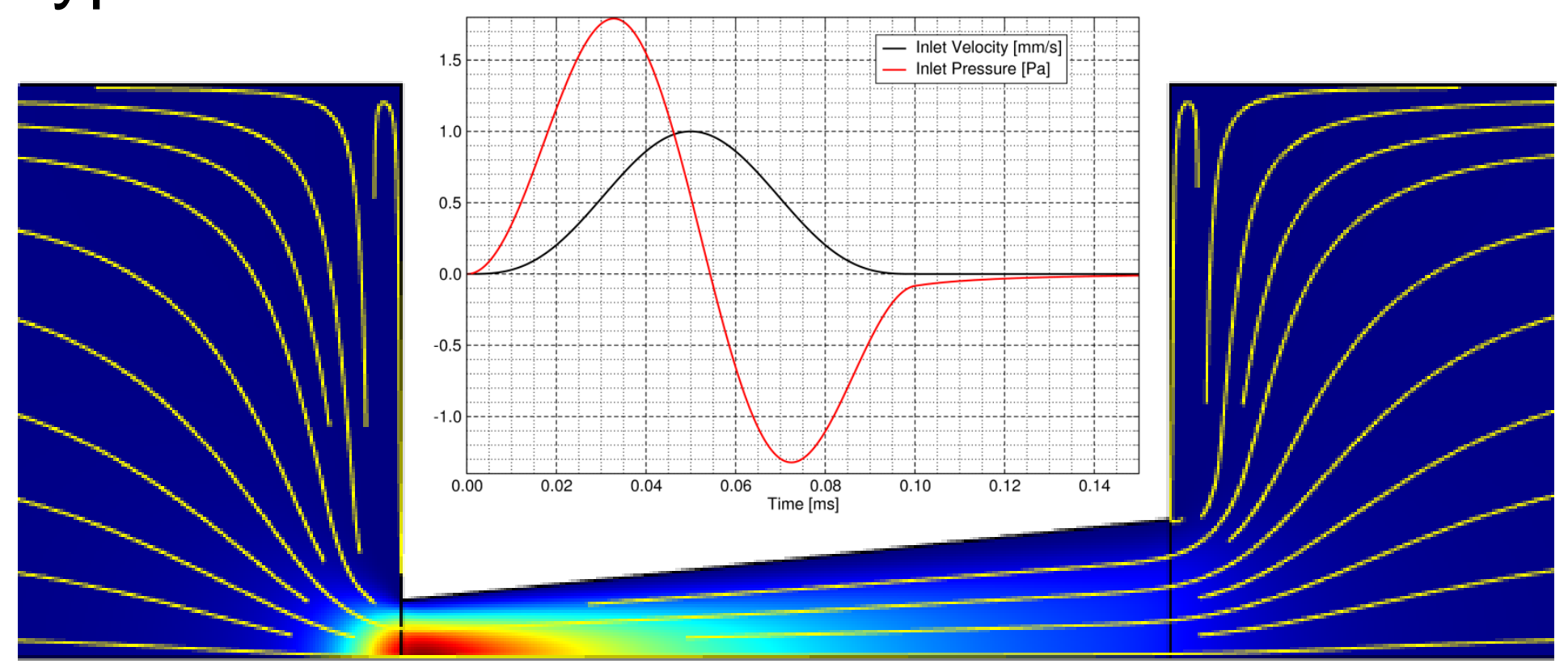

○ Reversible, laminar flow through hole $(\operatorname{Re} \approx 1)$

- No non-linear effects since we have low velocity

- Secondary motions in time-dependent cases 


\section{Dynamic Flow Resistance}

$\square$ Tapered Holes without End Corrections

$$
\begin{gathered}
\mathrm{Z}_{\text {Taper }}=j \rho \omega \int_{0}^{L} \frac{1}{\sigma_{x}}\left[1-\frac{2}{k_{x} \sqrt{-j}} \frac{J_{1}\left(k_{x} \sqrt{-j}\right)}{J_{0}\left(k_{x} \sqrt{-j}\right)}\right]^{-1} d x \\
k_{x}=r_{x} \sqrt{\rho \omega / \eta} \\
\sigma_{x}=\pi r_{x}^{2} / A \\
r_{x}=r_{1}+\left(r_{2}-r_{1}\right) x / L
\end{gathered}
$$

- Easily calculated numerically using codes such as Octave, MatLab, or Mathematica

- Value computed at each frequency point 


\section{Dynamic Flow Resistance}

\section{- Tapered Holes Dynamic End Corrections}

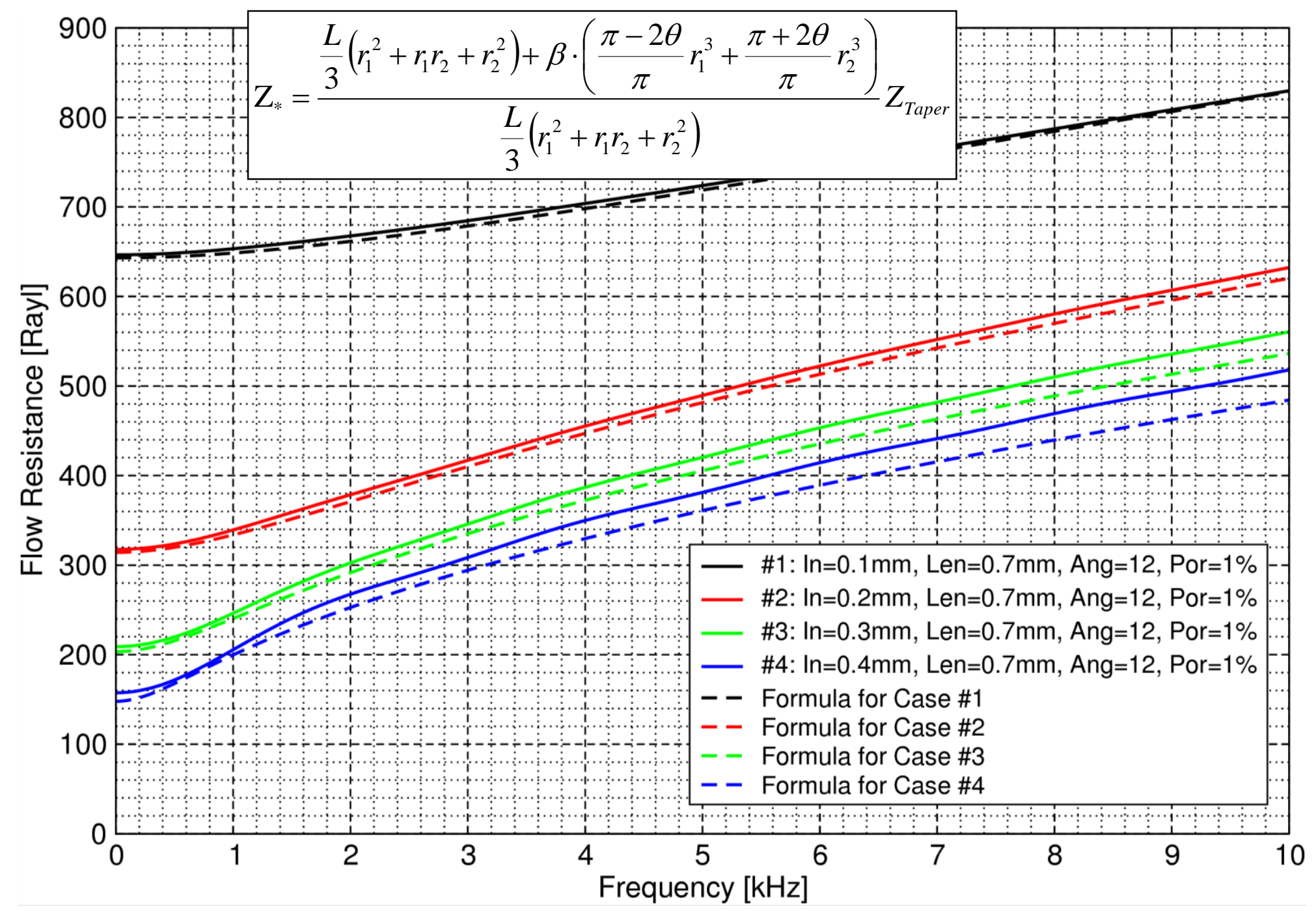


The above formulae apply only to non-metallic panels of low thermal conductance. If the microperforated panel is made of sheet metal or other material of high thermal conductance, the effect of heat conduction must be accounted for. Crandall[5] discussed the acoustical properties of metal tubes in some detail. The air is compressed adiabatically in ordinary sound fields. But inside a metal tube, the part of air near the tube wall will be kept at a constant temperature, any heat produced wiII

If the microperforated panel is made of sheet of metal or other material of high thermal conductance, the effect of heat conduction must be accounted for.

Crandall ${ }^{[5]}$ discussed the acoustical properties of metal tubes in some detail. The air is compressed adiabatically in ordinary sound fields. But inside a metal tube, the part of air near the tube wall will be kept at a constant temperature, any heat produced will be conducted away by the tube wall.

$$
\begin{gathered}
r=\frac{}{d^{2}} \frac{-}{p} k_{r} \\
m=0.294(10)^{-3} \frac{t}{p} k_{m},
\end{gathered}
$$

and

$$
\frac{r}{m}=\frac{1140}{d^{2}} \frac{k_{r}}{k_{m}}
$$

for mieroperforated panel of metal or other materials of high thermal conductivity. The constants $k_{r}$ and $k_{m}$ are still given by Eqs. (14) and (15), but now 


\section{Model Comparison - Model Setup}

口 CFD Models - InterNoise 2011

- Time domain

- Incompressible

- Isothermal

- 2D axisymmetric

- Inlet: Hann-windowed, $5 \mathrm{kHz}$ half-sine

- Maximum velocity of $1 \mathrm{~mm} / \mathrm{s}$

- Outlet pressure set of $0 \mathrm{~Pa}$

$\circ$ Run for at least $0.5 \mathrm{~ms}$

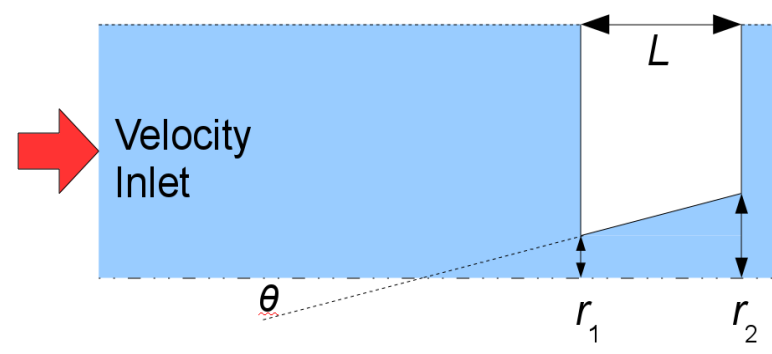

Inlet velocity profile
- Acoustic Models - NoiseCon 2014

- Frequency domain, harmonic waves

- Compressible

- Including energy equation

- 2D axisymmetric

- Non-reflecting inlet with $1 \mathrm{~Pa}$ incident

$\circ$ Resulting face velocity up to $2.4 \mathrm{~mm} / \mathrm{s}$

- Anechoic outlet

o Run from 50 to $10,000 \mathrm{~Hz}$

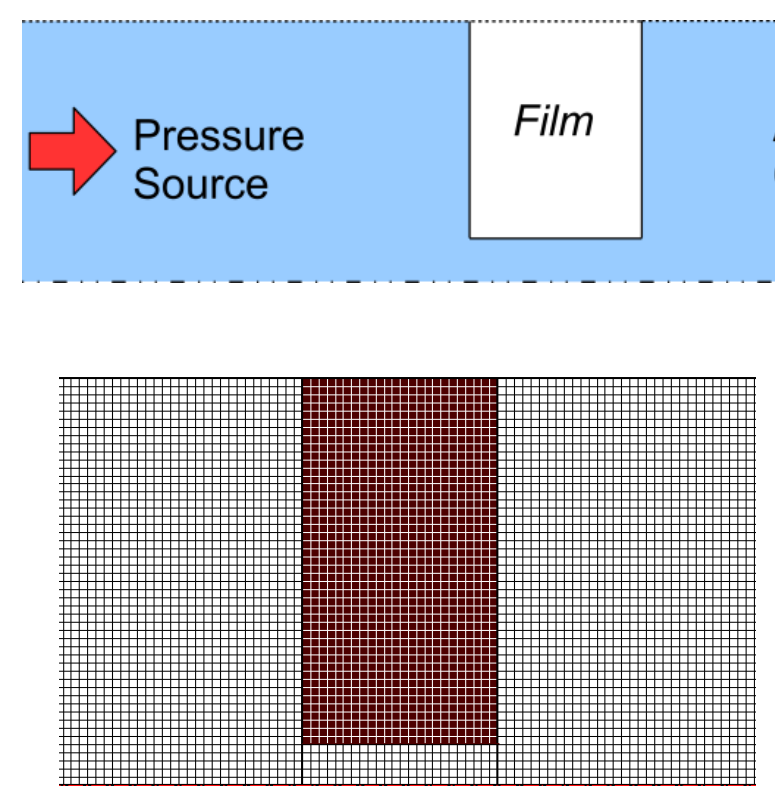

Anechoic Outlet
Typical mesh 


\section{Model Comparison - Model Equations}

口CFD Models - InterNoise 2011

- Incompressible Navier-Stokes equations

- Momentum and Continuity

$$
\begin{aligned}
& \rho \frac{\partial \mathbf{u}}{\partial t}+\rho(\mathbf{u} \cdot \nabla) \mathbf{u}=\nabla \cdot\left[-p \mathbf{I}+\mu\left(\nabla \mathbf{u}+(\nabla \mathbf{u})^{T}\right)\right] \\
& \nabla \cdot \mathbf{u}=0
\end{aligned}
$$

$\mathrm{p}$ - pressure

I - unit vector

$\rho$ - density (constant)

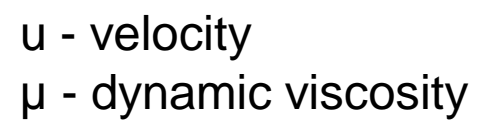

- At the surface of the film: $\mathbf{u}=0$ acoustic Models - NoiseCon 2014

- Linearized, harmonic Navier-Stokes equations $a \rightarrow a_{0}+a e^{i o t}$

- Momentum, Continuity, and Energy

$$
\begin{aligned}
& i \omega \rho_{0} \mathbf{u}=\nabla \cdot\left[-p \mathbf{I}+\mu\left(\nabla \mathbf{u}+(\nabla \mathbf{u})^{T}\right)-\frac{2 \mu}{3}(\nabla \cdot \mathbf{u}) \mathbf{I}\right] \\
& \frac{i \omega}{\rho_{0}}\left(\left.p \frac{\partial \rho_{0}}{\partial p}\right|_{T}+\left.T \frac{\partial \rho_{0}}{\partial T}\right|_{p}\right)+\rho_{0} \nabla \cdot \mathbf{u}=0 \\
& i \omega \rho_{0} C_{P} T=\nabla \cdot(k \nabla T)-i \omega p \frac{T_{0}}{\rho_{0}} \frac{\partial \rho_{0}}{\partial T} \\
& p \text { - pressure } \\
& \text { u - velocity } \\
& T \text { - temperature } \\
& \rho \text { - density } \\
& k \text { - thermal conductivity } \mu \text { - dynamic viscosity } \\
& C_{P} \text { - specific heat at constant pressure } \\
& \text { I - unit vector }
\end{aligned}
$$

- At the surface of the film: $\mathbf{u}=\mathbf{u}_{\text {film }}$ 


\section{Model Comparison - Transfer Impedance}

-CFD Models - InterNoise 2011

- Pressure taken at inlet and outlet

- $1.7 \mathrm{~mm}$ and $5.0 \mathrm{~mm}$ away from film

- Fourier transform for impedance

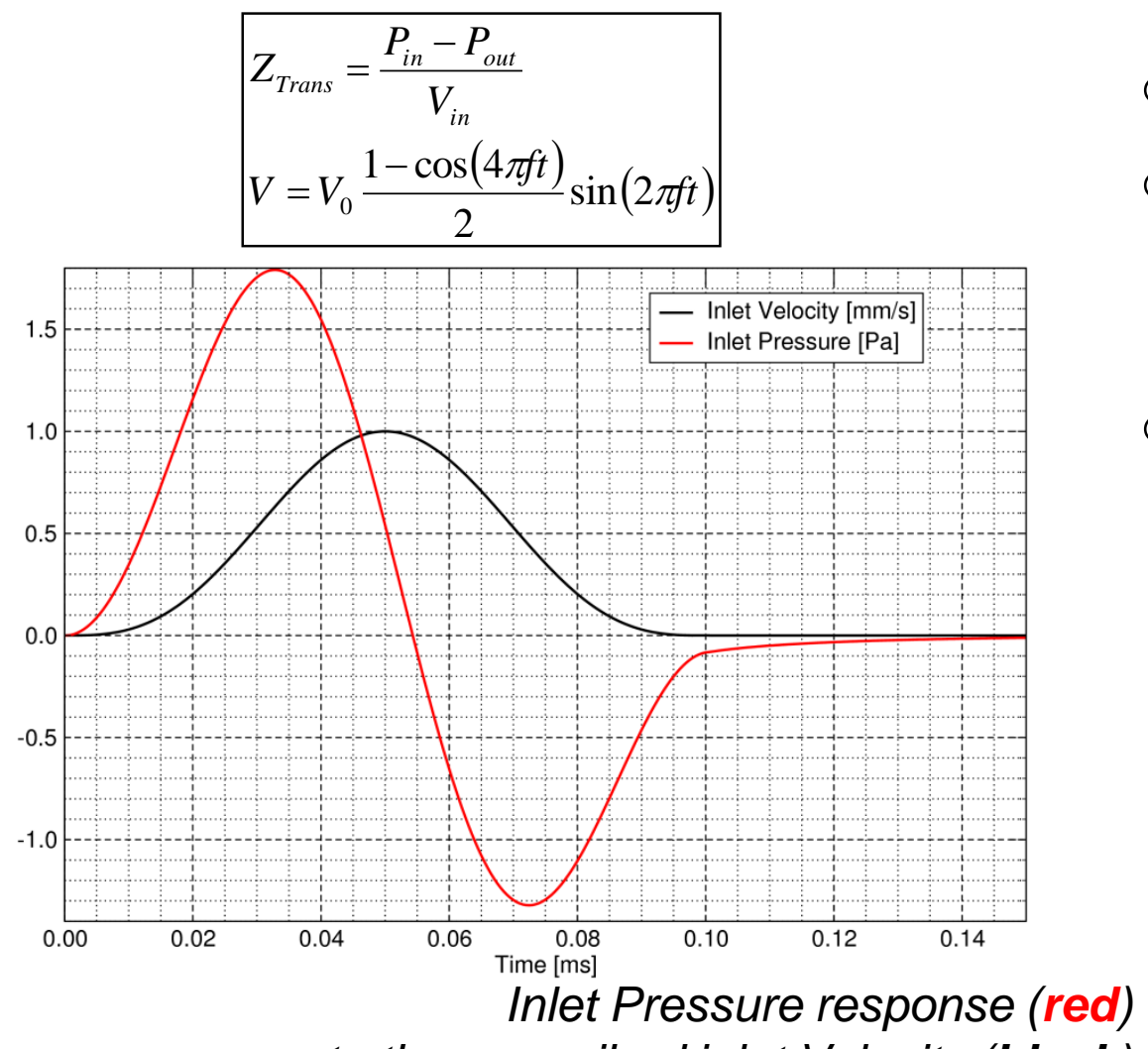

to the prescribed inlet Velocity (black) $\square$ Acoustic Models - NoiseCon 2014

- Pressure probes spaced away from film

- $2.50 \mathrm{~mm}$ and $3.75 \mathrm{~mm}$ up- and downstream

- Already in Fourier space

- Pressure and Velocity on front and back surfaces of film were determined from incident, reflected, and transmitted waves

- Transfer impedance computed using the 4-probe method from ASTM E2611-09

$$
Z_{\text {Trans }}=\frac{P_{0}}{V_{0}}-\frac{P_{L}}{V_{L}}
$$




\section{Rigid Film - Transfer Impedance}

$\square$ Thermal losses affect the Resistance only

- There are no thermal losses at an adiabatic boundary

\begin{tabular}{|ll|}
\hline \multicolumn{3}{|c|}{ Film Properties } \\
- Film Thickness $\quad 400 \mu \mathrm{m}$ \\
- Hole Diameter $\quad 170 \mu \mathrm{m}$ \\
- Porosity & $1 \%$ \\
\hline
\end{tabular}

- Acoustic and CFD models match when adiabatic boundary conditions are applied

$$
Z_{\text {Trans }}=Z_{C F D}-j \omega \rho_{\text {air }}\left(L_{\text {in }}+L_{\text {out }}\right)
$$

\section{$\square$ CFD calculations require additional correction}

- Need to account for the reactance of the air in the inlet and outlet regions
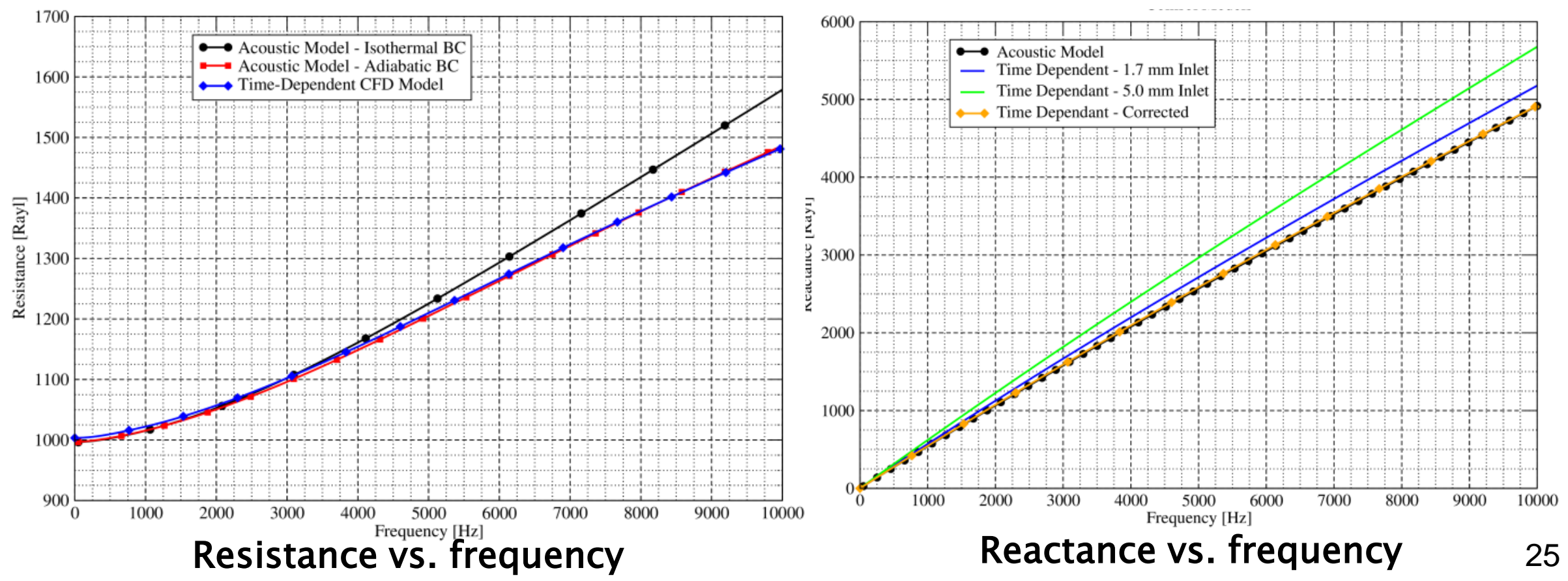


\section{Rigid Film - Thermal Losses}

$\square$ Thermal energy losses are proportional to the temperature gradient squared

- Losses are concentrated over whole front surface, and only a little within the perforation

(unlike Maa who modeled thermal losses occurring within the perforation)

- Losses are asymmetric front-to-back (acoustic wave is incident from below)

- Losses increase with the frequency (Scale is $1 / 30^{\text {th }}$ of viscous plots, so $1 / 900^{\text {th }}$ the energy loss)

$\left\langle E_{\text {loss }}\right\rangle_{k}=\frac{k}{T}\left\langle|\nabla T|^{2}\right\rangle$
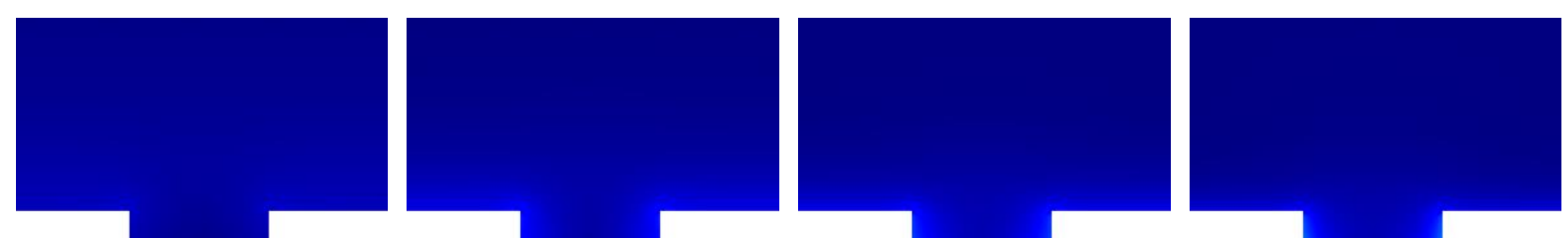

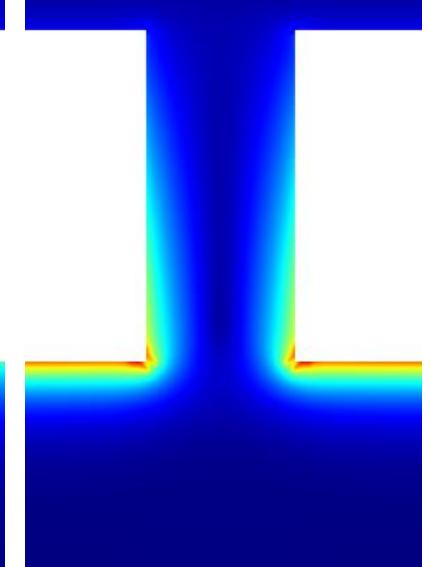

$5,000 \mathrm{~Hz}$ 


\section{Rigid Film - Losses Compared and Effective Absorption}

$\square$ Thermal losses are significantly smaller than viscous losses ( $<5 \%$ up to $10 \mathrm{kHz}$ )
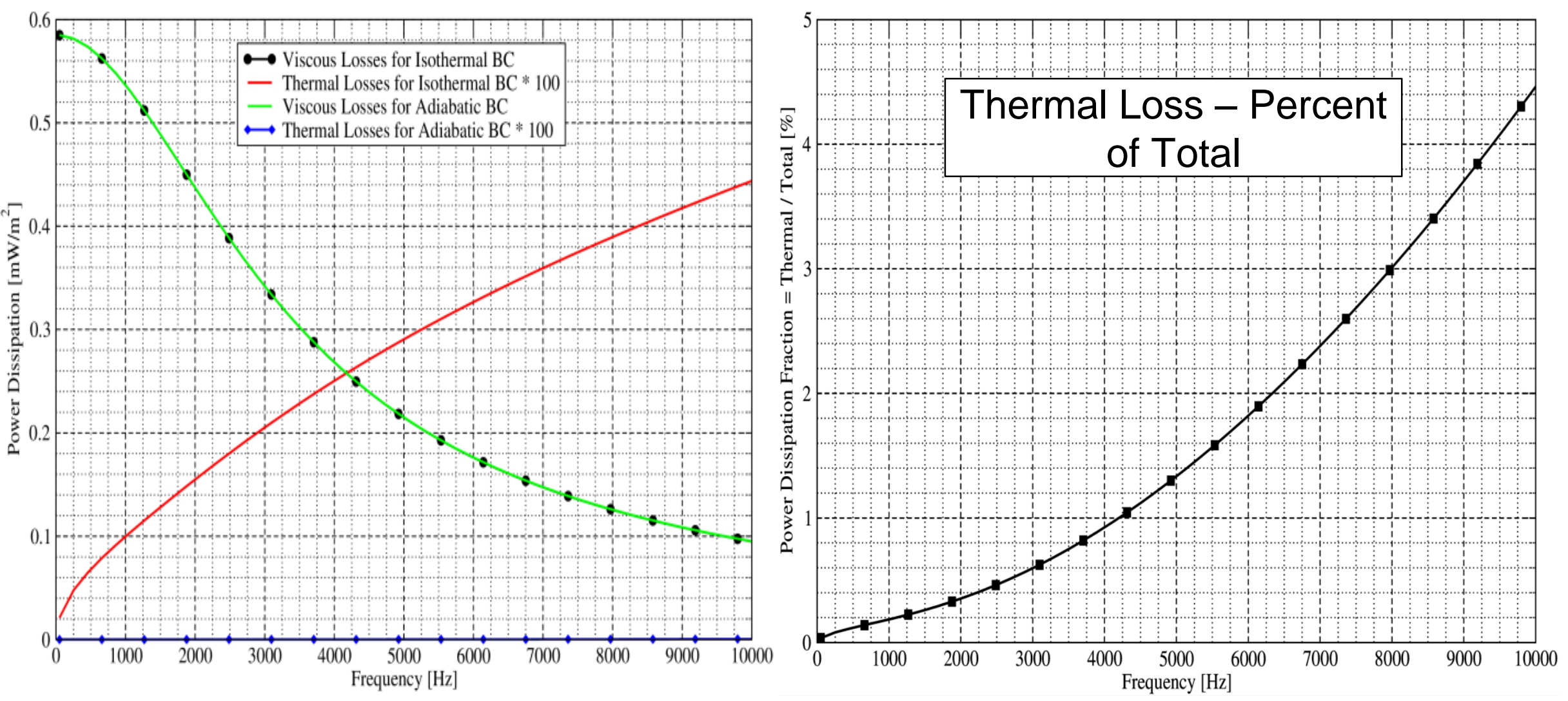


\section{Rigid Film - Losses Compared and Effective Absorption}

$\square$ Thermal boundary conditions (adiabatic vs. isothermal) are not significant for absorption

- Infinite film in free space

- Film in impedance tube with anechoic termination

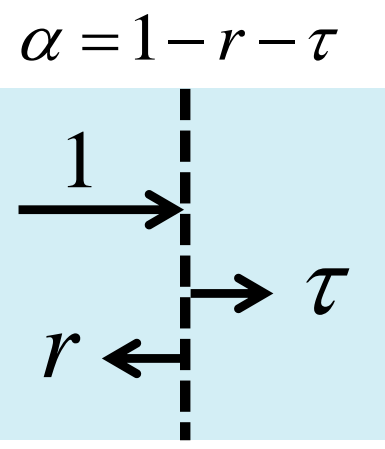

Absorption is the fraction of normally incident acoustic intensity not reflected or transmitted by the film.

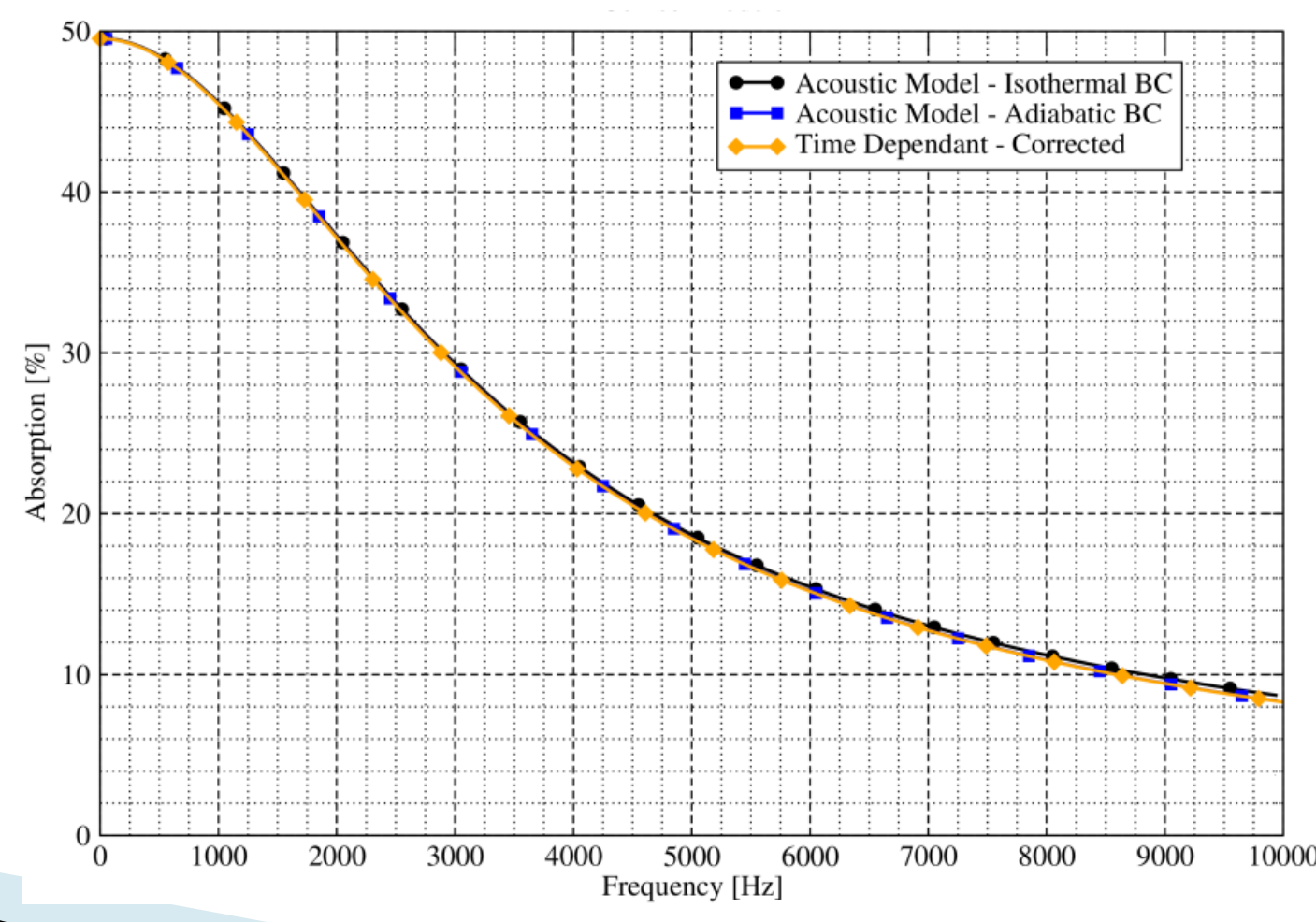




\section{Summary on Thermal Losses \\ $\square$ Thermal losses:}

- Increase with frequency

- Occur over the full incident face of the film

- Contributions from within the perforations are negligible

- For moving films, losses occur on both sides of the film

but the total thermal loss is almost identical to that of a rigid wall

- Contribute to the acoustic resistance, but not the reactance

- Are less than $5 \%$ of the total energy loss for practical films below $10 \mathrm{kHz}$

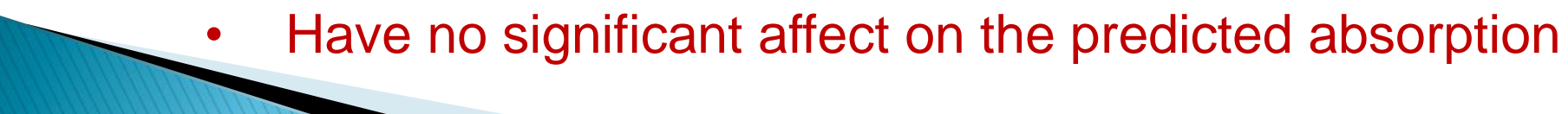
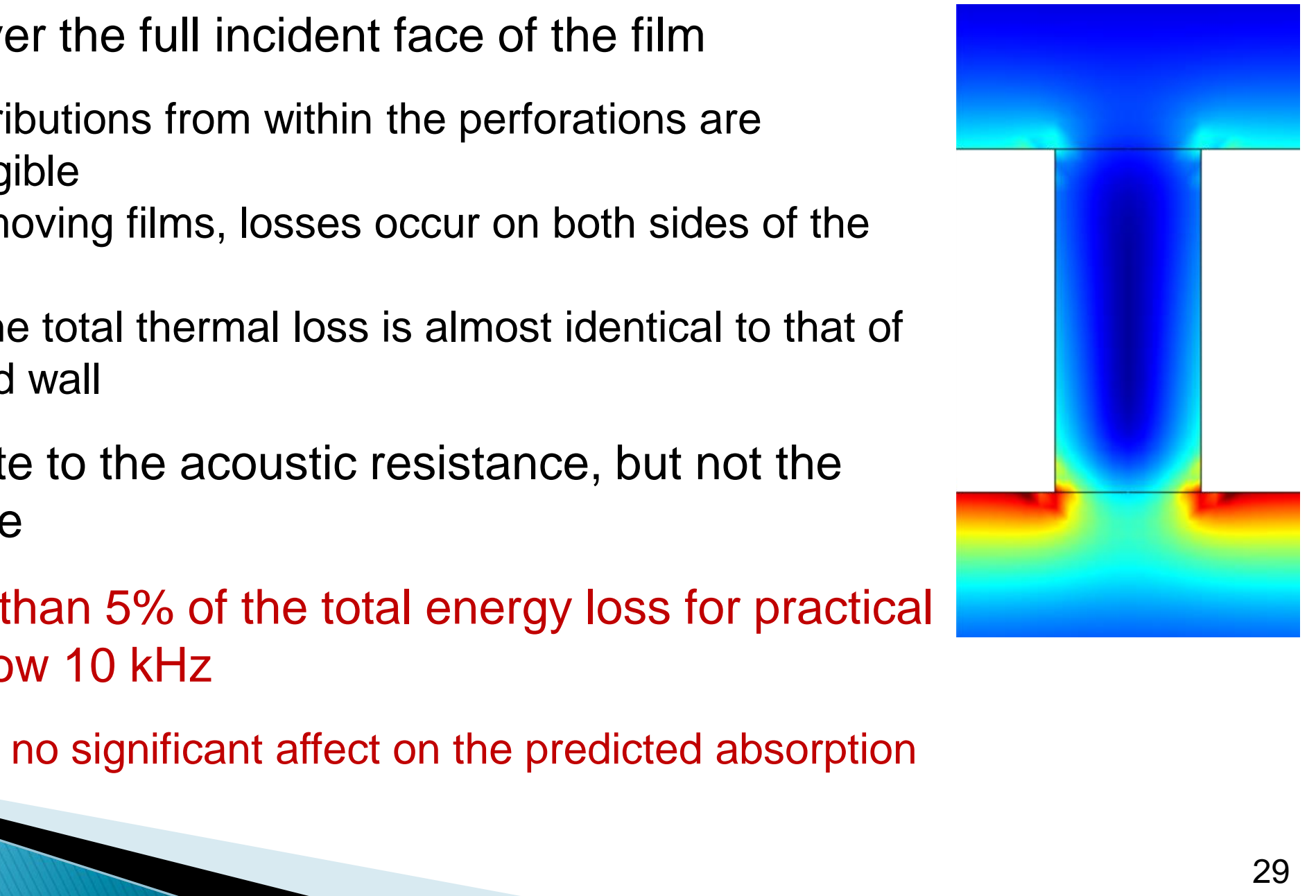


\section{Film Flexibility}

\section{3-dimensional model}

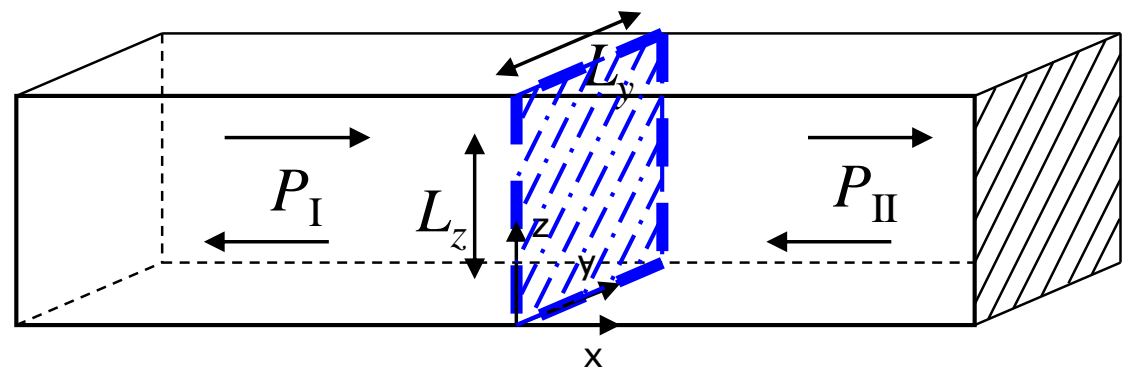

Only symmetric modes exist

$$
\begin{aligned}
& \text { Sound pressure in each region } \\
& P_{I}=e^{-j k x}+\sum_{m=0}^{\infty} \sum_{n=0}^{\infty} B_{m n} \cos \left(k_{2 m} z\right) \cos \left(k_{2 n} y\right) e^{j k_{k m 2 n} x^{x}} \\
& P_{I I}=\sum_{m=0}^{\infty} \sum_{n=0}^{\infty} C_{m n} \cos \left(k_{2 m} z\right) \cos \left(k_{2 n} y\right)\left(e^{-j k_{r 2 m} x}+e^{j k_{2,2 m}(x-2 L)}\right) \\
& k_{2 m}=\begin{array}{rrrr}
\frac{2 m \pi}{L_{z}} \quad k_{2 n}=\frac{2 n \pi}{L_{y}} & k_{x_{2 m 2 n}}=\sqrt{k^{2}-k_{2 m}^{2}-k_{2 n}^{2}} & \left(k>k_{2 n}+k_{2 m}\right) \\
(m, n=0,1,2, \ldots) & =-j \sqrt{k^{2}-k_{2 m}^{2}-k_{2 n}^{2}} & \left(k<k_{2 n}+k_{2 m}\right)
\end{array}
\end{aligned}
$$

\section{Displacement of membrane}

for simply supported BC

Solid part $d_{s}=\sum_{m=1}^{\infty} \sum_{n=1}^{\infty} A_{m n} \sin \left(k_{2 m-1} z\right) \sin \left(k_{2 n-1} y\right)$

Fluid part $\quad d_{f}=\sum_{m=0}^{\infty} \sum_{n=0}^{\infty} F_{m n} \cos \left(k_{2 m} z\right) \cos \left(k_{2 n} y\right)$ for clamped BC

Solid part $\quad d_{s}=\sum_{m=0}^{\infty} \sum_{n=0}^{\infty} A_{m n}\left\{\cos \left(k_{2 m} z\right)-1\right\}\left\{\cos \left(k_{2 n} y\right)-1\right\}$

Fluid part $d_{f}=\sum_{m=0}^{\infty} \sum_{n=0}^{\infty} F_{m n} \cos \left(k_{2 m} z\right) \cos \left(k_{2 n} y\right)$

Taewook Yoo, J. Stuart Bolton, Jonathan H. Alexander and David F. Slama, "Absorption of finite-sized micro-perforated panels with finite flexural stiffness at normal incidence," Proceedings of NOISE-CON 2008, Dearborn, Michigan, July 28-31, 2008. 


\section{Flexural Stiffness Effect}

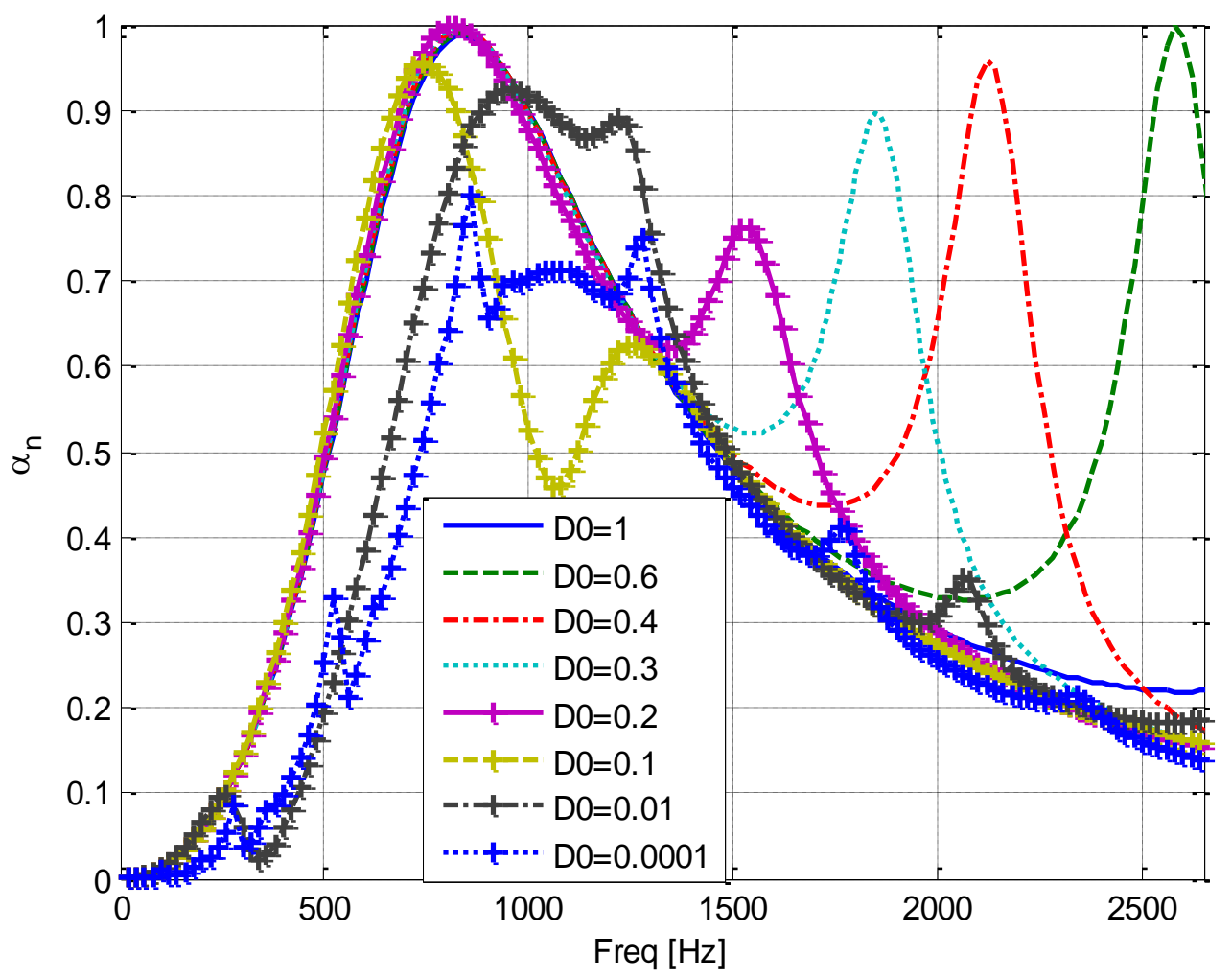

Depending on the flexural stiffness, the absorption performance can be enhanced with a proper loss factor

\begin{tabular}{|c|c|c|c|c|c|c|c|}
\hline $\begin{array}{c}d \\
{[\mathrm{~mm}]}\end{array}$ & $\begin{array}{c}t \\
{[\mathrm{~mm}]}\end{array}$ & $\begin{array}{c}D \\
{\left[\mathrm{~N} \cdot \mathrm{m}^{2}\right]}\end{array}$ & loss factor in $D$ & $\begin{array}{c}T \\
{[\mathrm{~N}]}\end{array}$ & $\begin{array}{c}\text { Mass/area } \\
{\left[\mathrm{kg} / \mathrm{m}^{2}\right]}\end{array}$ & $N$ & $\begin{array}{c}\text { Size } \\
{[\mathrm{mm}]}\end{array}$ \\
\hline 0.45 & 1.588 & $\begin{array}{c}1,0.6,0.4,0.3,0.2,0.1, \\
0.01,0.0001\end{array}$ & 0.05 & 0 & 0.1631 & 160000 & $63.5 \times 63.5$ \\
\hline
\end{tabular}




\section{Limp Perforated Film - Velocity and Phase}

$\square$ Relative motion

- Most significant for light films at low frequency

- Shown here for a density of $50 \mathrm{~kg} / \mathrm{m}^{3}$ at $150 \mathrm{~Hz}$

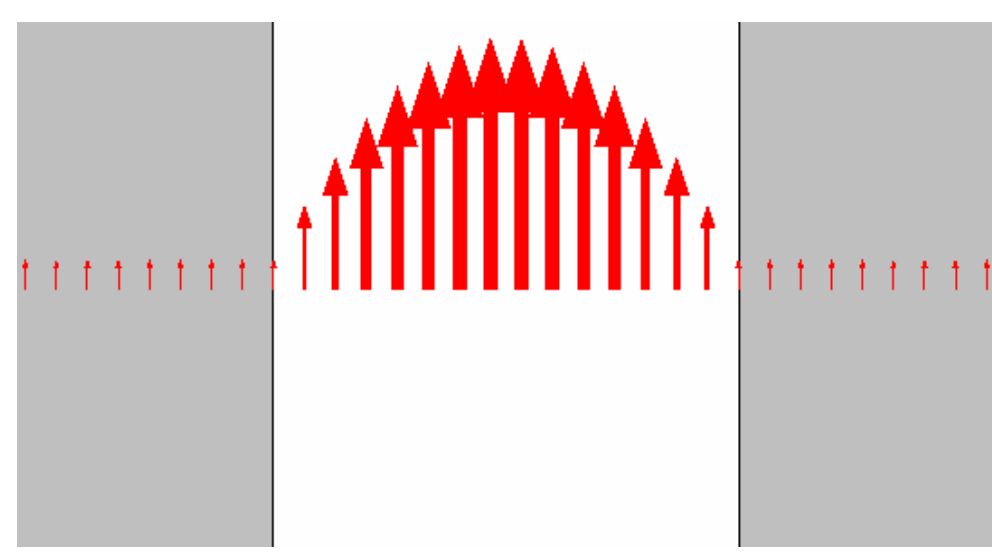

Film
Air
Film

Fluid-structure interaction
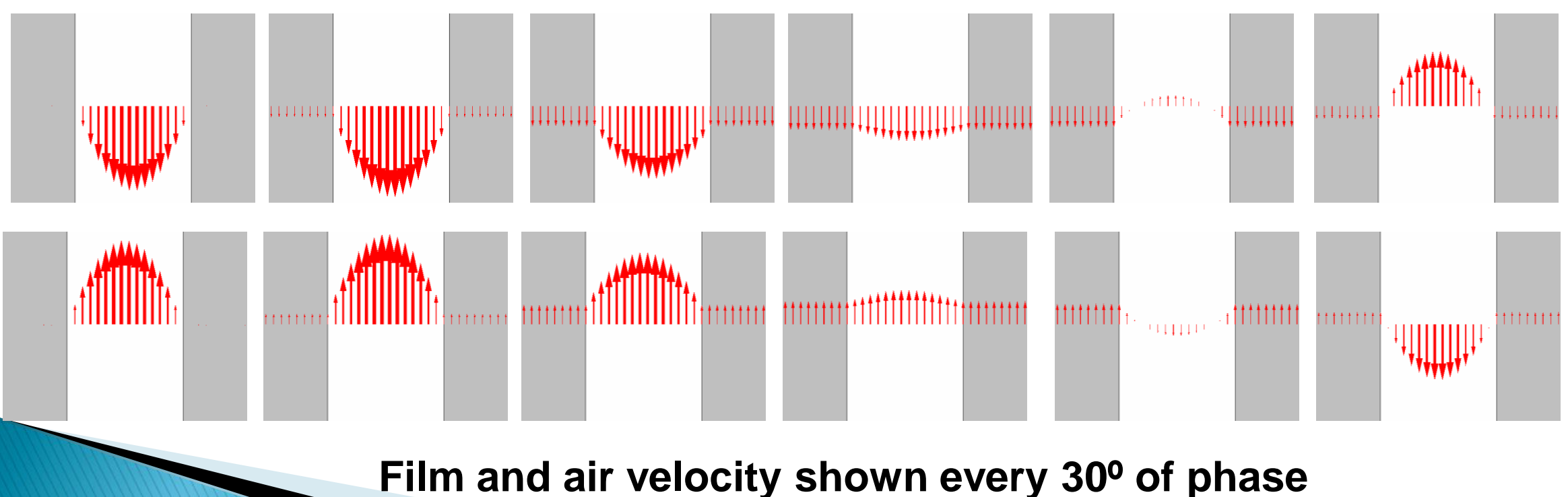

Film and air velocity shown every $30^{\circ}$ of phase 


\section{Solid Limp Film - Model Details}

$\square$ Velocity of the film depends on the film's mass / density

- Film moves as one solid block, in unison

o Film was modeled as an elastic solid

$\square$ Negligible thermal absorption ( $<0.3 \%$ )

\section{Film Properties}

- Film Thickness

- Elastic Modulus

- Poisson's Ratio

- Prediction by Pierce for normal-incidence absorption at a rigid surface (markers on plot)

- Allen D. Pierce, "Acoustics: An Introduction to Its Physical Principles and Applications", ASA, 1989.

Film Velocity

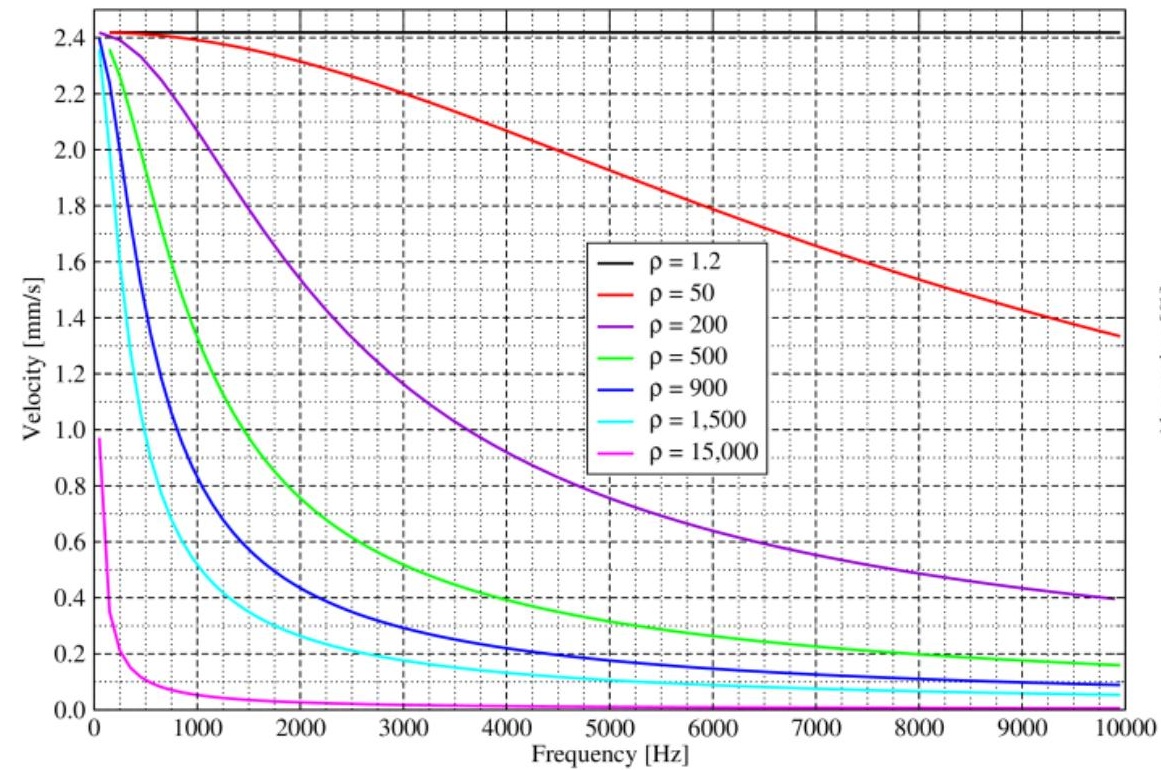

Absorption from Thermal Losses

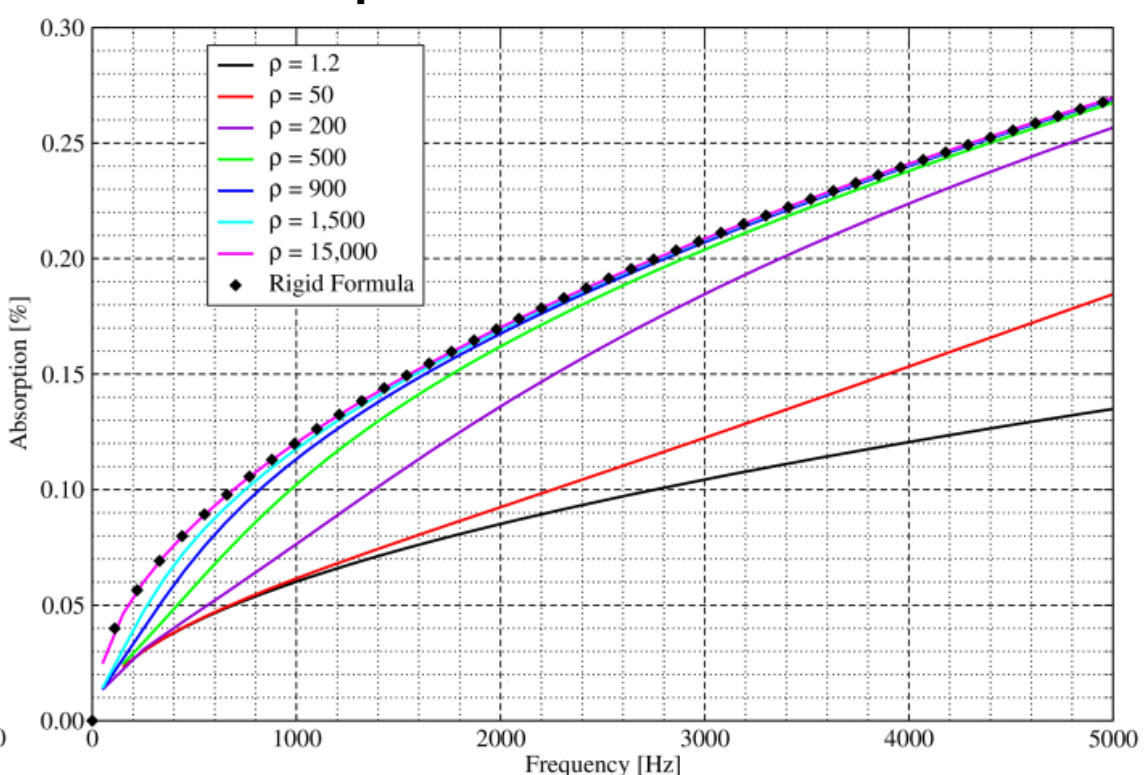




\section{Limp Perforated Film - Velocity Magnitude}

Film velocities are reduced, compared to a solid film

○ Airflow through the perforations reduces the surface pressure

o For example at $1 \mathrm{kHz}$, film velocities dropped by about 35\%

Air velocities through the perforations are reduced, compared to a rigid film

o Due to the film moving with the air

- Peak air velocity shifts to higher frequencies as the film mass decreases

- Air velocities are typically two orders of magnitude greater than film velocity

\begin{tabular}{|l|ll|}
\hline \multicolumn{2}{|c|}{ Film Properties } \\
& \multicolumn{3}{|c|}{ - Film Thickness } & $400 \mu \mathrm{m}$ \\
& - Hole Diameter & $170 \mu \mathrm{m}$ \\
& - Porosity & $1 \%$ \\
& - Elastic Modulus & $109 \mathrm{~Pa}$ \\
• Poisson's Ratio & 0.4 \\
\hline
\end{tabular}

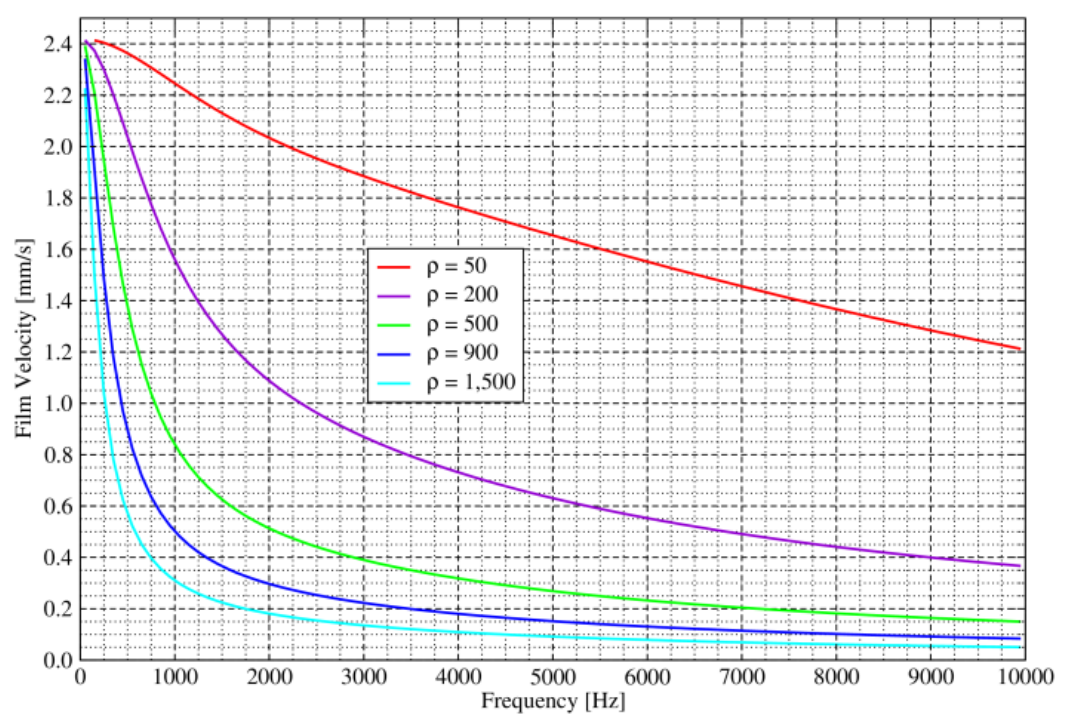

Film Velocity

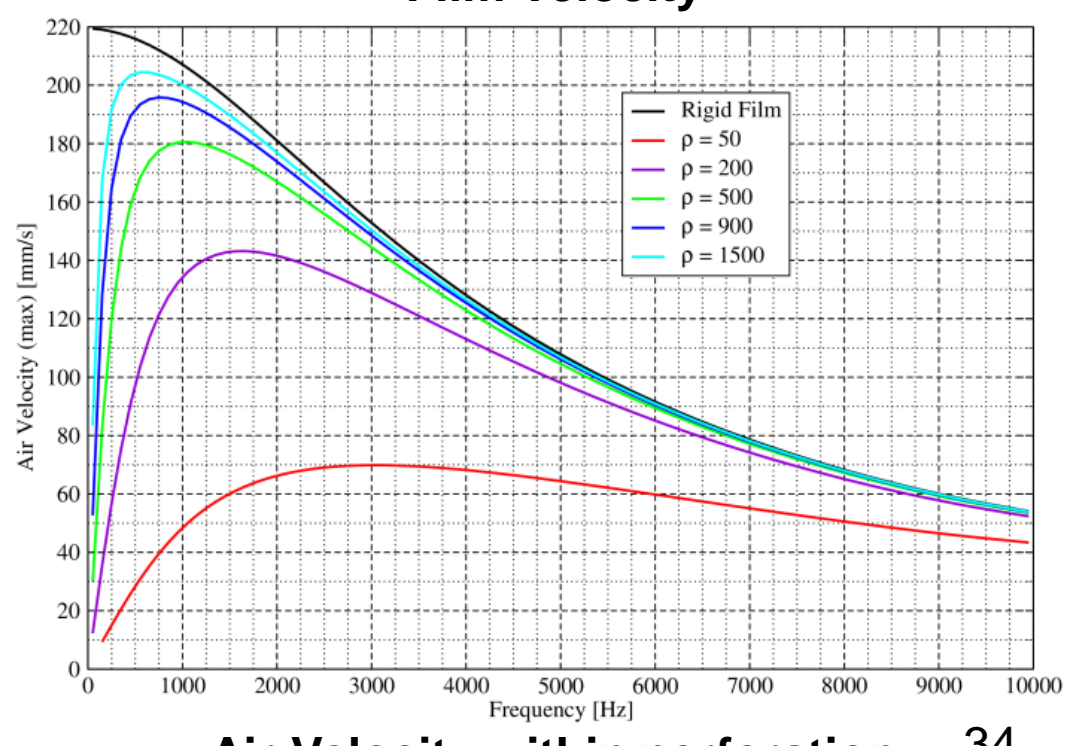

Air Velocity within perforation 


\section{Limp Perforated Film - Impedance}

Mass Law impedance for limp impervious sheet added in parallel to the impedance of a rigid perforated plate predicts response very well (markers)

- Resistance drops as mass decreases

- Reactance changes in non-intuitive manner

$$
Z_{\text {Film }}=\frac{1}{\frac{1}{Z_{\text {Rigid }}}+\frac{1}{Z_{\text {Sheet }}}}=\frac{j \omega m \cdot Z_{\text {Rigid }}}{Z_{\text {Rigid }}+j \omega m}
$$

o Low-frequency has an increase of reactance with mass

- High-frequency approaches rigid results more directly

Film Resistance - FSI models compared to formula

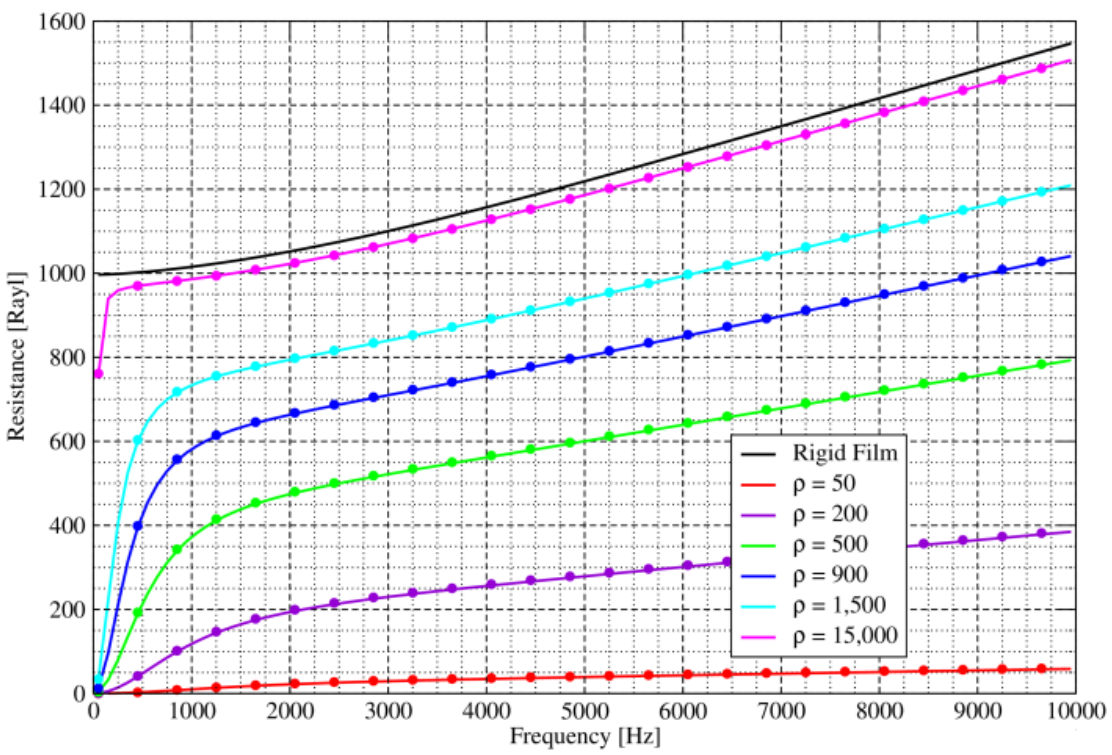

Film Reactance - FSI models compared to formula

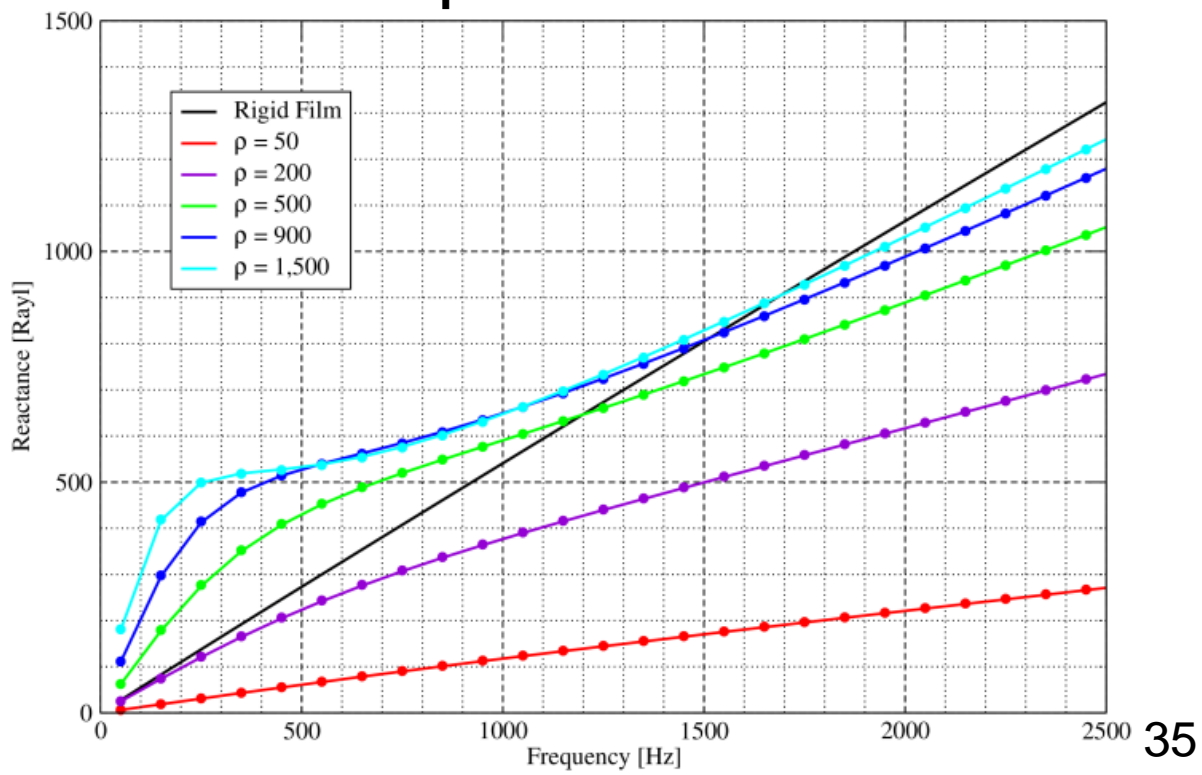




\section{Limp Perforated Film - Energy Loss}

- Thermal losses are much less than viscous losses, again $<5 \%$ even at $10 \mathrm{kHz}$
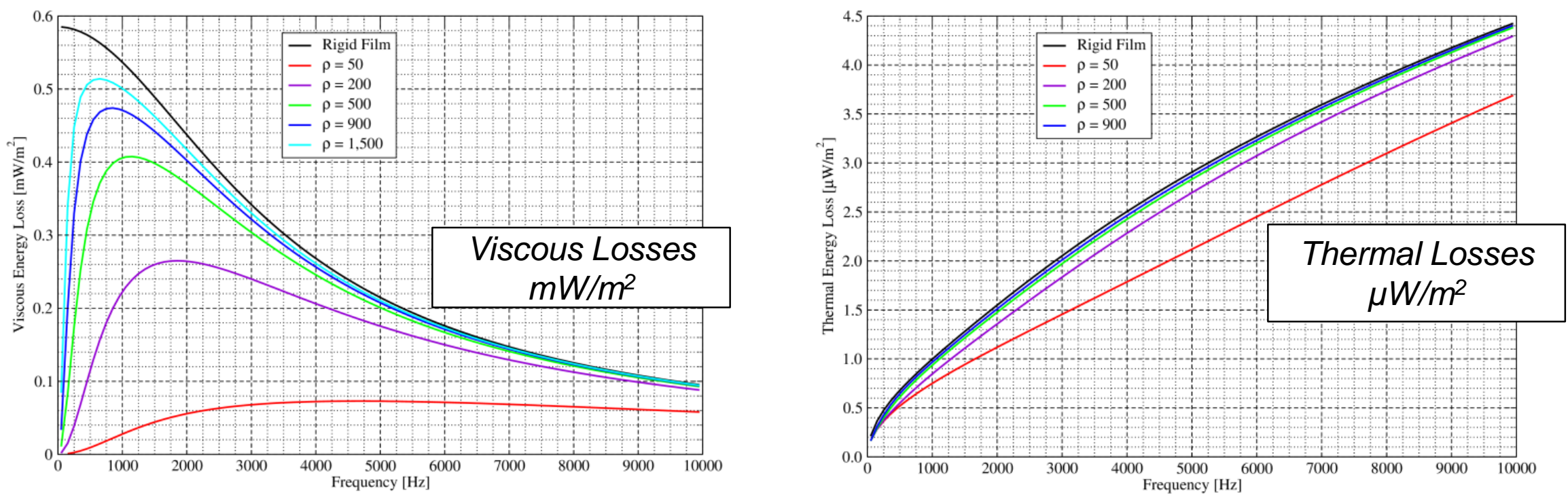

- For a film (shown at $450 \mathrm{~Hz}$ ), thermal losses can occur on both sides of the film (total < rigid)

Film density given in $\mathrm{kg} / \mathrm{m} 3$; color scale is from 0 to $0.1 \sqrt{W / m^{3}}$

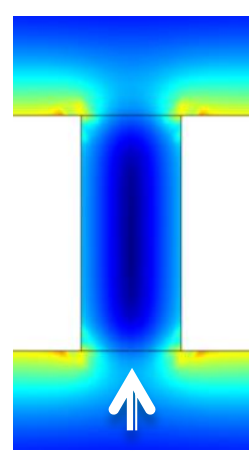

50

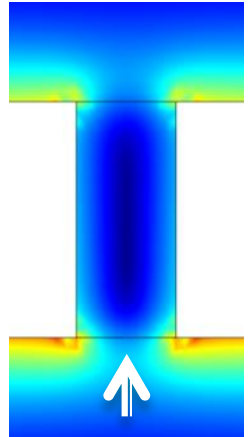

200

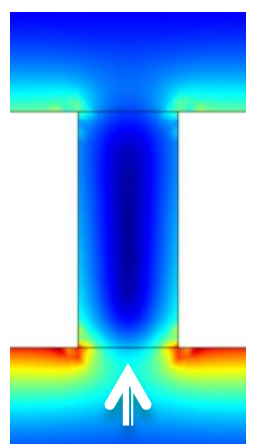

500

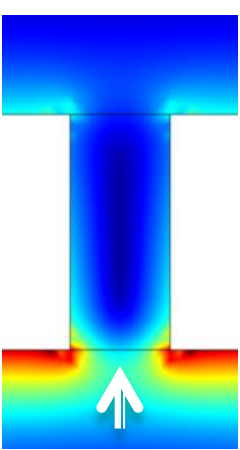

900

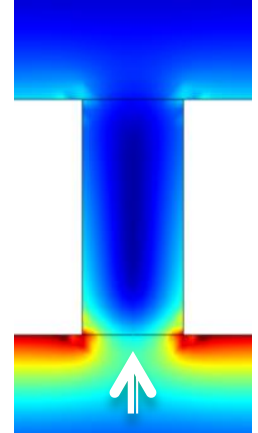

1,500

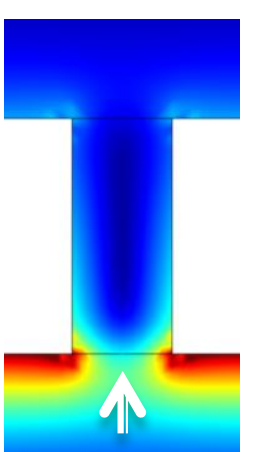

Rigid 


\section{Conclusions}

Computational modeling of MPP's has proven to be a powerful tool

$\square$ Has allowed identification of the correct origin of the resistive end correction

Accurate calculation of transfer impedance of MPP's with arbitrarily shaped holes

$\square$ For thermally conducting materials, thermal losses occur on surface of MPP (not within holes), but contribution to energy dissipation generally negligible.

$\square$ Solid - phase motion influences MPP transfer impedance, but large disparity between solid and fluid velocities allows transfer impedance to be calculated by parallel addition of rigid MPP and flexible impermeable film. 


\section{References}

- J. Stuart Bolton and Nicholas Kim, "Use of CFD to calculate the dynamic resistive end correction for microperforated materials," Acoustics Australia, Vol. 38, p. 134-139, 2010.

- Thomas Herdtle, J. Stuart Bolton, Nicholas Kim, Jon Alexander and Ronald Gerdes, "Transfer impedance of microperforated materials with tapered holes," Journal of the Acoustical Society of America, Vol. 134, 4752-62, 2013.

- Thomas Herdtle and J. Stuart Bolton, "Effect of thermal losses and fluid-structure interaction on the transfer impedance of microperforated films," Proceedings of NoiseCon 2014, Fort Lauderdale FL, September 2014.

For presentations go to: http://docs.lib.purdue.edu/herrick/ or search for "Herrick epubs" 